\title{
MsSTiR \\ LOW-COST SITE-ASSEMBLED SOLAR COLLECTOR DESIGNS FOR USE WITH HEAT PUMPS
}

\author{
JOHN W. ANDREWS AND WILLIAM WILHELM
}

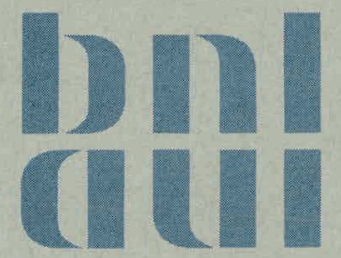

May 1977

\section{DEPARTMENT OF APPLIED SCIENCE}

BROOKHAVEN NATIONAL LABORATORY ASSOCIATED UNIVERSITIES, INC. UNDER CONTRACT NO. EY-76-C-02-0016 WITH THE UNITED STATES ENERGY RESEARCH AND DEVELOPMENT ADMINISTRATION 


\section{DISCLAIMER}

This report was prepared as an account of work sponsored by an agency of the United States Government. Neither the United States Government nor any agency Thereof, nor any of their employees, makes any warranty, express or implied, or assumes any legal liability or responsibility for the accuracy, completeness, or usefulness of any information, apparatus, product, or process disclosed, or represents that its use would not infringe privately owned rights. Reference herein to any specific commercial product, process, or service by trade name, trademark, manufacturer, or otherwise does not necessarily constitute or imply its endorsement, recommendation, or favoring by the United States Government or any agency thereof. The views and opinions of authors expressed herein do not necessarily state or reflect those of the United States Government or any agency thereof. 


\section{DISCLAIMER}

Portions of this document may be illegible in electronic image products. Images are produced from the best available original document. 


\title{
LOW-COST SITE-ASSEMBLED SOLAR COLLECTOR DESIGNS FOR USE WITH HEAT PUMPS
}

\author{
John W. Andrews and William Wilhelm
}

May 1977 


\section{N O T I C E}

This report was prepared as an account of work sponsored by the United States Government. Neither the United States nor the United States Energy Kesearch and Development Administration, nor any of their employees, nur any of their contractors, subcontractors, or their employees, makes any warranty, express or implied, or assumes any legal liability or responsibility for the accuracy, completeness or usefulness of any

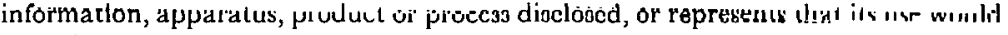
not infringe privately owned rights.

Printed in the United States of America

$$
\text { Available from }
$$

National Terhnical Information Service

$$
\text { U.S. Department of Commerce }
$$

5285 Port Royal Road

Springfield, VA 22161

Price: Printed Copy $\$ 45 ;$ Microfiche $\$ 3.00$

July 1977

$$
4^{0^{\partial}} \quad 380 \text { copies }
$$




\section{Table of Contents}

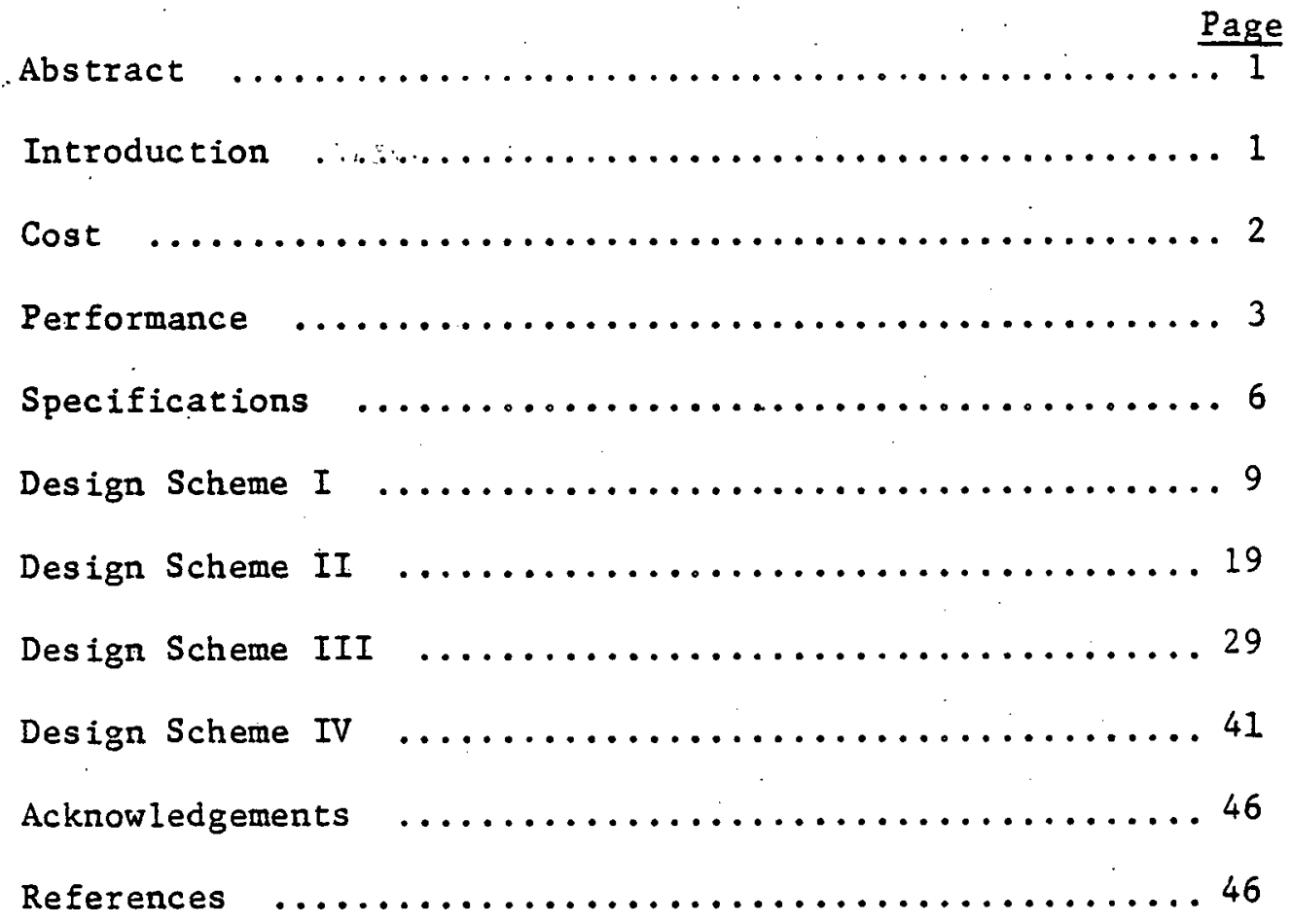




\begin{tabular}{|c|c|c|c|c|c|c|}
\hline Figure & $1-$ & Scheme & $I$ & Drawing & 1 & Section Views and Details..... 15 \\
\hline igure & $2-$ & - Scheme & I, & Drawing & 2 & Construction Sequence........16 \\
\hline igure & $3-$ & - Scheme & I, & Drawing & 3 & Snap-In Absorber Unit.........17 \\
\hline Pigure & $4-$ & Scheme & $I I$ & Drawing & 1 & Section Views and Details.....26 \\
\hline Figure & $5-$ & Scheme & II, & Drawing & 2 & Construction Sequence........27 \\
\hline Figure & $6-$ & - Scheme & $I I$ & Drawing & 3 & Construction Sequence........28 \\
\hline Figure & $7-$ & Scheme & III, & Drawing & 1 & Section Views and Details.....37 \\
\hline Figure & $8-$ & Scheme & III, & Drawing & 2 & Construction Sequence........38 \\
\hline Figure & $9-$ & Scheme & III, & Drawing & 3 & Construction Sequence........39 \\
\hline Figure & $10-$ & Scheme & IV, & Drawing & 1 & Section Views and Details.....47 \\
\hline Figure & $11-$ & - Scheme & IV, & Drawing & 2 & Construction Sequence........48 \\
\hline igure & $12-$ & - Scheme & IV, & Drawing & 3 & Construction Sequence.........49 \\
\hline
\end{tabular}




\begin{abstract}
Four low cost solar collector designs have been produced for use in solar assisted heat pump systems. Three principles guided the design: the use of air as the heat transfer medium, the use of on-site easy-toinstall construction rather than modularized prefabricated construction, and the collection of solar energy at reduced temperatures.
\end{abstract}

\title{
Introduction
}

The main impediment to the widespread use of solar energy today is the high capital cost of equipment needed to collect and store solar energy and deliver it to the desired point of use. It has been our intent to design solar collectors which will be low enough in cost to be economically attractive in today's energy market. Our approach is based on three principles: The use of air as the heat-transfer medium, the use of on-site easy-to-install construction rather than modularized prefabricated construction, and the collection of solar energy at reduced temperatures. By using air as the heat transfer medium we avoid many problems associated with collector corrosion, leakage, and freeze-up. By relying on on-site construction we eliminate the rigid, heavy material-intensive panels which arise, in factory prefabrication, from the need for structural rigidity during shipment and installation. And by operating at reduced temperatures 
we obtain increased collection efficiencies and avoid the need for multiple glazings, selective surfaces, and carefully designed insulation.

The low-cost collectors that result from this design effort are intended to be used in solar-assisted heat-pump systems. Heat pumps supplied with energy in the temperature range $70-120 \mathrm{~F}$, which these collectors will typically provide, operate with good efficiency and with reduced electric power consumption.

\section{Cost}

The cost per unit area of these solar collector designs is expected to be less than that of prefabricated modular designs for two important reasons:

1) Lower markup in the handling and distribution system.

2) Reduced material requirement.

Different handling, distribution, warehousing, and retailing techniques have evolved to convey different products from the point of manufacture to the point of end use. The price of the product to the consumer reflects the cost incurred in these handling techniques. Modularized and prefabricated solar collectors are handled as hardware products and have experienced a cost markup from manufacturer to consumer of trom 3 to 5 . This large markup factor has magnified the originally cheaper factory labor cost to the point that it is much more expensive than job-site labor, when paid by the conoumer.

Nevertheless, job-site labor must be kept low. The solar collector designs described in this report are intended to reduce job-site labor to a minimum, and in many cases this labor should be no more than that required to assemble prefabricated modules which tend to be heavy, requiring expensive lifting equipment. 
Building construction materials are distributed in bulk and sold to builders in quantity. The builder, acting in the equivalent role of the retailer, is under intense competitive pressure. As a result the overall markup in this system is much less. Solar collector designs to be marketed through this system should be much more favorably priced. The collectors described herein are specifically designed to be sold in pieces, as building materials, rather than as prefabricated appliances, thus taking advantage of the construction-material marketing system.

Prefabricated modularized collectors must be shipped, warehoused, and handled without damage. This handing imposes rigidity requirements on the module. Considerable material is required in the frame and other support structure to solve these handling problems. This added material can be saved if the collector is assembled on the job site from precut or stamped material. In some of our designs the modular support frame is eliminated entirely. The cost savings resulting from the elimination of material and the reduced handling markup should result in a significantly lower price to the consumer.

\section{Performance}

We have calculated, using the method of Whillier, ${ }^{1}$ the expected efficiency of the collectors proposed in this paper. An insolation rate of $300 \mathrm{Btu} / \mathrm{ft}^{2}-\mathrm{hr}$ at normal incidence was assumed, with an upward heat loss coefficient $U_{L}$ of $1.2 \mathrm{Btu} / \mathrm{ft}^{2}-\mathrm{hr}-\mathrm{F}$. A curve of predicted collector efficiency was calculated as a function of the standard temperature-difference measure

$$
\frac{\Delta T}{I}=\left[\frac{(T \text { outlet }+T \text { inlet })}{2}-T \text { ambient }\right] / I
$$


where $\mathrm{T}$ inlet and $\mathrm{T}$ outlet are the inlet and outlet temperatures, in ${ }^{\circ} \mathrm{F}$, of the heat-transfer air passing through the collector. T ambient is. the temperature of the outside ambient in ${ }^{\circ} \mathrm{F}$, and $I$ is the insolation rate in Btu/ft ${ }^{2}-h r$. The calculated efficiency at $\Delta T / I=0$ was $72 \%$. A study of measured collector efficiencies prepared by Dubin-Bloome Associates ${ }^{2}$ showed values for this quantity ranging from $54 \%$ to $88 \%$. The value of $\Delta T / I$ for which the efficiency drops to zero is 0.69 . This is near the low end of the range of values for this quantity, most of the collectors in the Dubin-Bloome study having measured values between 0.6 and 1.2. However, since our coliector is intended for low-temperature use, this is not necessarily a great drawback.

One feature which is common to all of the designs presented in this report is the shaping of the absorber plate to obtain a $3: 1$ ratio between heat transfer area to the air within the collector and collector surface area. This is achieved by bending the absorber plate into a vee pattern, as can be seen in the drawings. We arrive at the need for a $3: 1$ ratio from a consideration of the heat-transfer rate from the absorber plate to the collector air stream. If we assume operation at $50 \%$ efficiency at an insolation rate of $300 \mathrm{Btu} / \mathrm{ft}^{2}-\mathrm{hr}$, then we want to be able to collect $150 \mathrm{Btu} / \mathrm{ft}^{2}-\mathrm{hr}$. We estimate an average temperature difference between absorber plate and collector air stream of $20 \mathrm{~F}$, and a heat-transfer coefficient of $2.5 \mathrm{Btu} / \mathrm{ft}^{2}-\mathrm{hr}-\mathrm{F}$ at an air-stream velocity of $300 \mathrm{ft} / \mathrm{min}$. We then have a heat transfer of $50 \mathrm{Btu} / \mathrm{ft}^{2}-\mathrm{hr}$ from the absorber plate to the air stream, which means that we need three times as much absorber plate area within each square foot to transfer $150 \mathrm{Btu} / \mathrm{ft}^{2}-\mathrm{hr}$. The $20 \mathrm{~F}$ temperature difference between absorber and collector air stream is consistent with the results of our efficiency 
calculations. $50 \%$ efficiency operation is attained at a $\Delta \mathrm{T} / \mathrm{I}$ value of 0.2 , or $\Delta T=60 \mathrm{~F}$. Under the same conditions the absorber plate is $80 \mathrm{~F}$ above ambient, -.. or twenty degrees higher than the average of inlet and outlet temperatureș.

To keep fan power requirements to a minimum, we decided upon a maximum air velocity of $300 \mathrm{ft} / \mathrm{min}$. From this we wish to calculate the required thickness of the air-flow passage beneath the absorber plate. Our design-example collector is $20 \mathrm{ft}$ long and $32 \mathrm{ft}$ wide, which means that it must be able to collect $20 \times 32 \times 150=96000 \mathrm{Btu} / \mathrm{hr}$. The volume of air needed to absorb $96000 \mathrm{Btu}$ is given by

$$
Q=\rho V c_{p} \Delta T,
$$

where $Q$ is the heat absorbed $(96000 \mathrm{Btu}) ; \rho$ is the density $\left(0.07 \mathrm{lb} / \mathrm{ft}^{3}\right.$ near $100 \mathrm{~F}) ; c_{p}$ is the heat capacity $(0.24 \mathrm{Btu} / \mathrm{Ib}-\mathrm{F})$; and $\Delta \mathrm{T}$ is the inlet-tooutlet temperature rise $(30 \mathrm{~F}) . V$ is then equal to $190000 \mathrm{ft}^{3}$. If in one hour this air travels $300 \times 60=18000 \mathrm{ft}$, then the collector cross-sectional area must equal $190000 / 18000$ or $10.6 \mathrm{ft}^{2}$. If the width is $32 \mathrm{ft}$, then the height must be $10.6 / 32$ or $0.33 \mathrm{ft}$ or $4 \mathrm{in}$. The air flow requirement in cubic feet per minute is $190000 / 60$ or $3200 \mathrm{cfm}$ for the $640 \mathrm{ft}^{2}$ designexample collector.

Envisioned in the design of the system to use these collectors is the minimization of duct length by the provision of air-water heat exchange in the attic, immediately below the collectors. The water is then pumped to storage in the basement, where it feeds energy to the evaporator of a waterair or water-water heat pump. In addition to miniwizing fan power by ninimizing the length of ductwork through which the air must be blown, we also have water storage, allowing us to use a water-air or water-water heat pump, 
enabling a smaller temperature difference to exist between storage and the evaporator than would be the case with an air-water or air-air heat pump. Al1 water in the system is within the insulated shell of the house, and therefore freezeup will not occur. It may be necessary to take steps to prevent reverse thermosyphoning of the collector air, such as by provision of a one-way set of louvers somewhere in the air stream.

\section{Specifications}

The following set of specifications contains drawings and descriptions for each of the four solar collector designs.

The design description for each design will consist of three parts:

A) A construction sequence description following the installation process as it actually occurs on the roof.

B) A parts glossary, containing a description of each part and its nominal dimensions, together with a discussion of any intricate details in the construction of the part.

C) A discussion of materials specifications and design options.

Reference will be made in the design description to a set of production drawings. Reference to a specific detail will be by means of a circle divided into upper and lower halves, containing a set of reference numbers. This symbol will guide the reader to the appropriate place in the drawings.

Below the line there will either be a number or a number plus a Roman numeral. The number is the number of the drawing on which the detail apears. The Roman numeral, if present, indicates the panel within the drawing in which the detail appears.

Above the line there will be a number or a number-plus-letter combin= ation. This is the label for the specific detail referred to. 


\section{PAGES 7 to 8 WERE INTENTIONALLY LEFT BLANK}




\section{DESIGN SCHEME I}

\section{A. Construction Sequence Description}

The idea underlying this design is to construct a continuos solar collector out of prefabricated 32 in $\times 48$ in. "snap-in absorber units". Each of these units contains the absorber plate, supported 4 in above the roof deck, and supporting members onto which the glazing material can be fastened. The snap-in absorber units overlap, and with provision for sealing the sides and ends, we have an enclosure beneath the absorber plate which is sealed against moderate pressure differences. The problem of rain leakage into the collector is also addressed in this design.

It is assumed in this design that the collector will be applied to a plane surface of plywood. Holes in the plywood for supply and return air will have been cut before construction of the collector begins.

Drawing 1 shows section views of the collector together with certain details. Drawing 2 shows the construction sequence. Drawing 3 is a detailed isometric of one snap-in absorber unit together with plane views of some of its component parts.

The first step in construction is to nail to the roof deck three sides of a rectangular structure of modified zees and channels which defines the boundary of the collector. (See Drawing 2, Panel I.) The side channel

$\frac{1}{2 I}$ absorber units. The end zees strips of metal $\left(\frac{2}{2 I}\right.$ and as to receive the wees in the absorber plate.

The second step is to install the snap-in absorber units (Drawing 2, Panel II). See also Drawing I, especially for a detail of the 
snap-in process. The left side of each absorber unit snaps in under the right side of the one to its left, after which its right side is nailed to the roof deck. The leftmost absorber units snap in to the side channels, which are shaped like the right side of an absorber unit' in order to receive them.

After all the absorber units are in place, the right side fascia the glazing , and the left side
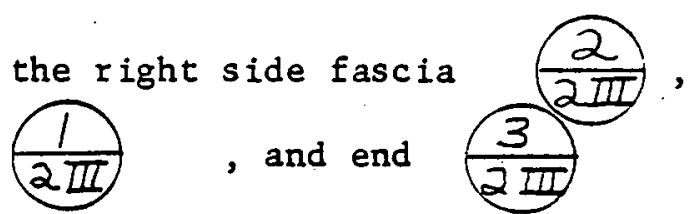
fascias are installed. The end fascias are screwed to the end zees through spacers $\frac{12}{3}$, and to the glazing. The spacers provide an exit path for rain which may have gotten to the absorber plate through imperfect seals in the glazing, and they also allow a small amount of air flow between the glazing and the absorber plate to keep the temperature from rising too high under stagnation conditions. At the high end the fascia goes over the glazing, while at the low end the glazing, to facilitate rain runoff.

The right side fascia ( 2 and 1 unit which hooks on to the rightmost absorber units at the roof deck level and at the level where the absorber plate terminates, 3 in above the roof deck. It is also screwed to the glazing.

Some consideration needs to be given to how the glazing is to be applied to the structure, once the absorber units are in place. They are not expected to support the point load of a man's weight. A ladder, fitted with a transverse beam spanning two or more absorber units, might solve the problem. After all the absorber units have been installed the glazing strips could be put on starting either at the top or the bottom, as long as care 
is taken that lower sheets are overlapped by those above.

\section{B. Parts Glossary}

The parts are described in the order in which they are applied during construction. Below is an alphabetical parts list, followed by the number of the article describing the part in this glossary.

\section{PART}

ARTICLE NO. IN GLOSSARY

Absorber Unit, Snap-In
Channel, Left Side
Fascia, End
Fascia, Left Side
Fascia, Right Side
Glazing
Zee, End

\section{Left Side Channel $\frac{1}{2 I}$ and $\frac{D 1}{1}$}

Overall dimensions 50 in. $\times 4 \cdot 3 / 4$ in. $\times 2$ in. Nominal thickness of sheetmetal 0.016 in. Nominal thickness of truss web 0.060 in. This modified channel has an open-web truss support structure built in at the factory. The purpose of this piece is to provide a firm member to snap in the first absorber unit to its right. It also provides a pressure seal at the left edge of the collector.

2. End Zee $\frac{4}{2 I}$ and

Overall dimensions 32 in. $\times 413 / 16$ in. $\times 2$ in. Nominal thickness 0.060 in. Top and bottom flanges 1 in each. Interior and exterior pressure seals (2I and $\frac{3}{2 I}$ are notched to receive the vees in the absorber 
plate. The pressure seals are attached to the zee during the manufacturing process. Their dimensions are identical so that both can be cut to the same shape. The interior pressure seal must be bent longitudinally in order to be applied to the inside of the zee. The pressure-seal strips are 2 in. longer than the zees to allow overlap on each side; their nominal thickness is 0.016 in.

3. Snap-in Absorber Unit (Drawing 3 and Sections $A-A$ and $B-B$ of Drawing 1)

Since this part is the heart of this design it will be described in some detail. The overall dimensions of this unit are 50 in $\times 32$ in $\times 51 / 2$ in. The nominal thickness of the absorber plate is 0.012 in. Nominal thickness of truss webbing and straps is $0.060 \mathrm{in}$. Nominal thickness of the glazing support struts is $0.100 \mathrm{in.} \mathrm{Beginning} \mathrm{with} \mathrm{the} \mathrm{absorber} \mathrm{plate} \mathrm{itself,}$ we see that it is folded so that vees spaced 1 in apart protrude 1 in. downward from the general level of the absorber plate. The purpose of these vees is to facilitate heat transfer, giving a needed $3: 1$ ratio of absorber plate srea to roof area.

At the right hand edge the absorber plate has a lip, onto which the left edge of the next snap-in unit is attached. The absorber plate is supported from below by two open-web trusses $\left(\frac{4}{3}\right.$ and see also Section B-B of Drawing 1). Three metal straps

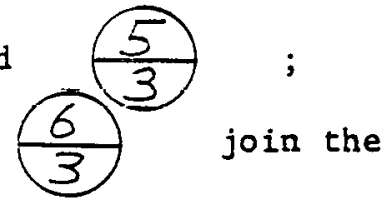
two trusses and are anchored to the left end of the absorber plate (see Detail (D3)

To the top. of the absorber plate are fastened three glazing support struts. These serve two purposes. As their name implies, they support the glazing and the glazing is fastened to them. They are also intended to provide some 
rigidity to the absorber plate, inhibiting downward sag of the vee system. They will of necessity have to be of fairly heavy gauge and be optimally contoured to do this job. The straps, trusses, and glazing struts are attached by spotwelding. In the present design, each snap-in absorber unit will require 48 of these joints.

4. Glazing (Drawing 2, Panel 3)

The glazing is to be a fiberglass-impregnated plastic such as "Kalwall" or "Filon". It is currently manufactured in $5 \mathrm{ft} \times 5 \mathrm{ft}$ rolls. We will assume a width of 51 in and a length equal to the horizontal dimension of the collector, which for our design is $32 \mathrm{ft}$. Thickness is $0.040 \mathrm{in}$. This design calls for corrugated glazing. The peak-to-trough height of the corrugations is $9 / 16$ in, while the lateral distance from one peak to the next is $22 / 3$ in, so that 12 full corrugation wavelengths will fit over each 32 in. width of absorber.

5. Right Side Fascia $\frac{2}{2 I}$ and $\frac{17}{1}$

Overall dimensions 50 in $\times 51 / 2$ in. $\times 11 / 2$ in. Nominal thickness 0.016 in. This fascia snaps onto the bottom strip of the truss of the rightmost snap-in absorber unit, providing a seal against moderate pressure differences and also a barrier against the entry of water into the collector.

\section{Left Side Fascia $\frac{1}{2 \pi}$ and}

Overall dimensions 50 in. $\times 41 / 2$ in. $\times 2$ in. Nominal thickness 0.016 in. This fascia is attached to the left side channel and to the glazing by means of screws.
7. End Fascia

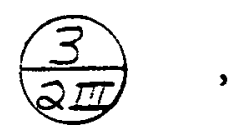
D5
, and

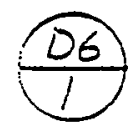

Overall dimensions 34 in $\times 41 / 2$ in. $\times 2$ in. Nominal thickness 0.016 in. The top flange of this fascia is scalloped to fit the glazing. If this proves 
very costly to fabricate with sheet metal, a high-temperature injectionmolded plastic might be considered, or the fascia might have to be redesigned. The fascia is screwed to the end zee through spacers $\frac{M 2}{3}$ and to the glazing. The screws through the glazing are placed at the peaks of the corrugations, to minimize rain leakage.

\section{Materials Specifications and Design Options}

The primary. fabrication material for this design is steel. Aluminum may be considered as an alternate if a suitable technique is available for making the many spot-welds at sufficiently low cost.

The design is drawn with corrugated glazing. Flat glazing should be considered an alternative design option. Since flat glazing does not have the rigidity in one dimension that corrugated glazing has, it may be necessary to provide more glazing support struts on the snap-in absorber units in this case.

All screws should be self-tapping, with integral plastic inserts under the heads to provide weatherproofing. 


\section{HIEME I}

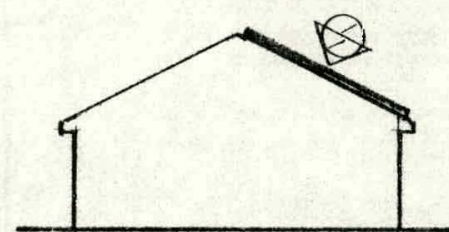

$\frac{\text { KEY ELEVTION }}{1,1-1.0^{\prime}}$

(2)

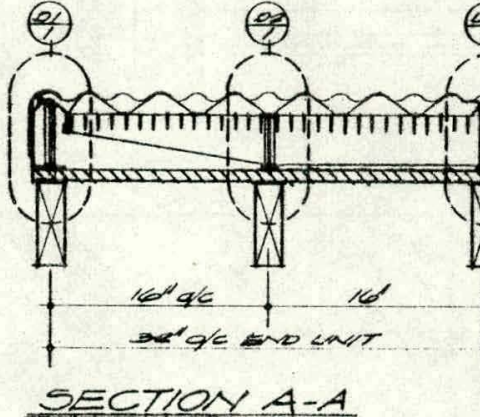

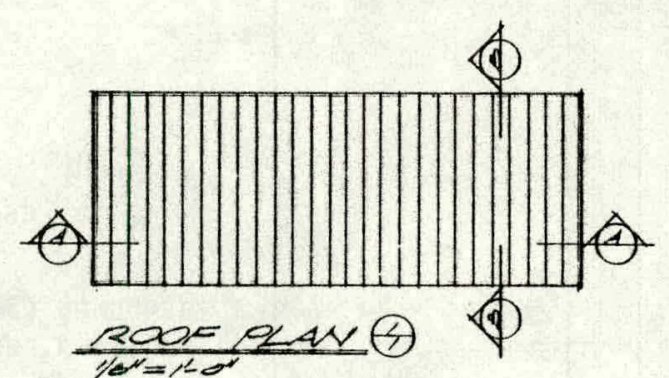

(9)

9 $101=10$

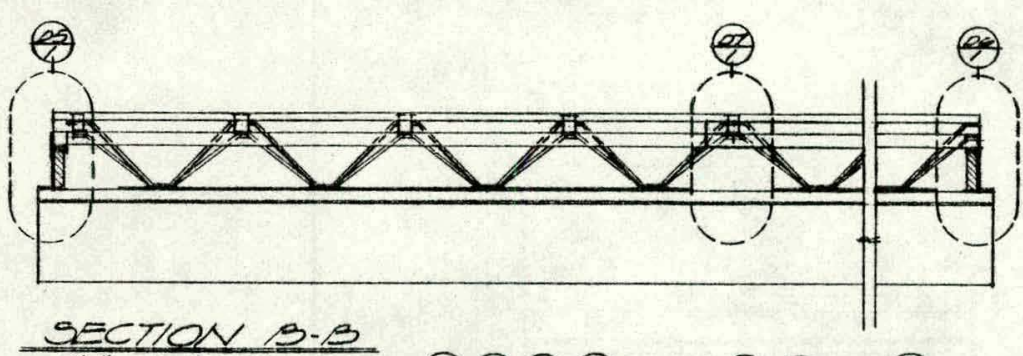

$\frac{\text { SECTION B-B }}{1 / 3^{2}-104}$

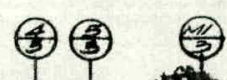

(2) 20

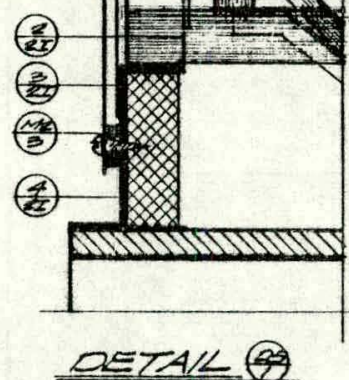
DETAKL (3) DETAKILOA SECTION A-A

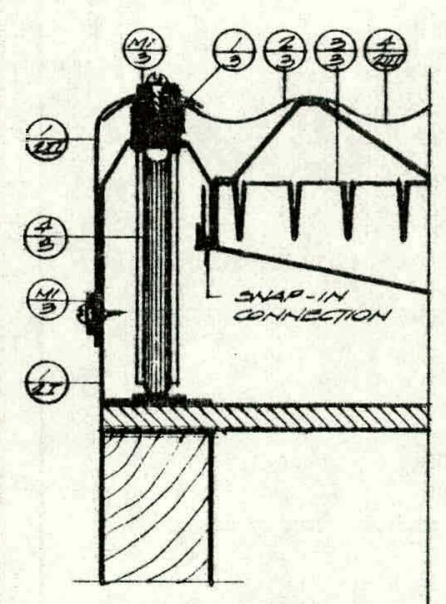

DETAK (2)

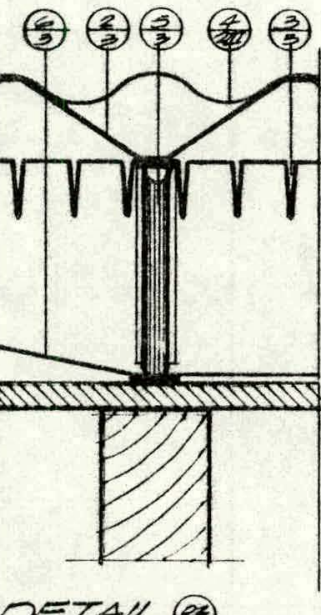

$0=T 41<0$

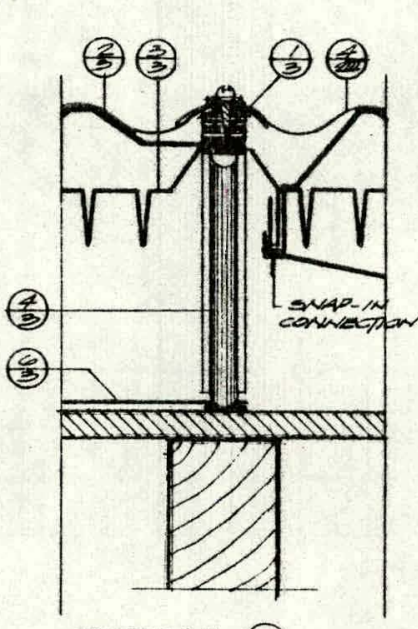

DETAK

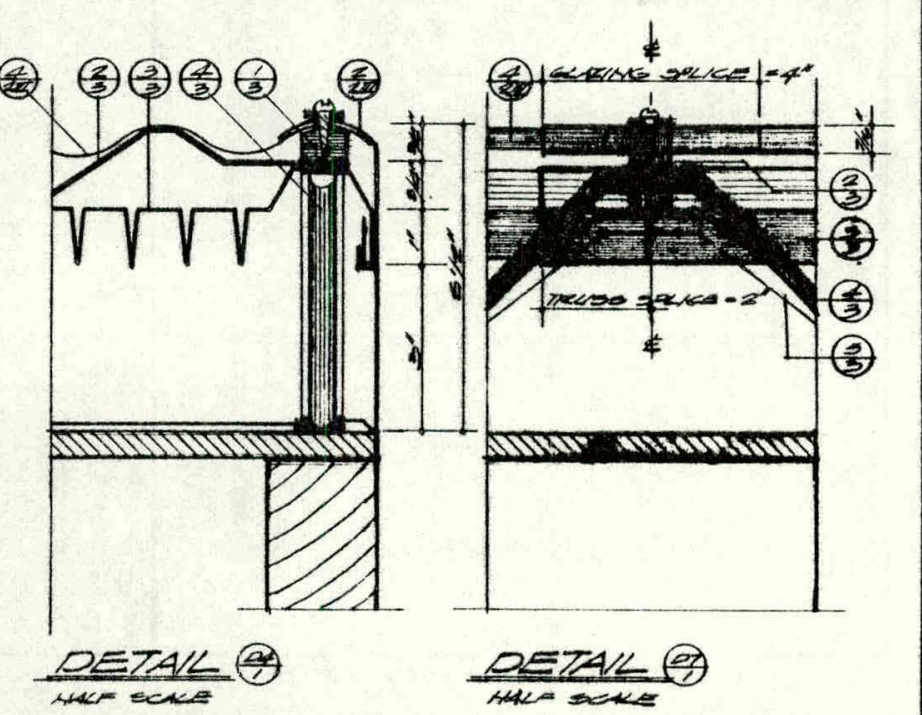

-DII: 10

Figure 1. Scheme I, Drawtrg 1 Section Views and Details 
CONSTRLTION SEQUENCE DRAWINGS

I PERMETER CONDITIONS II SNAP-IN ASSOREER LNIT

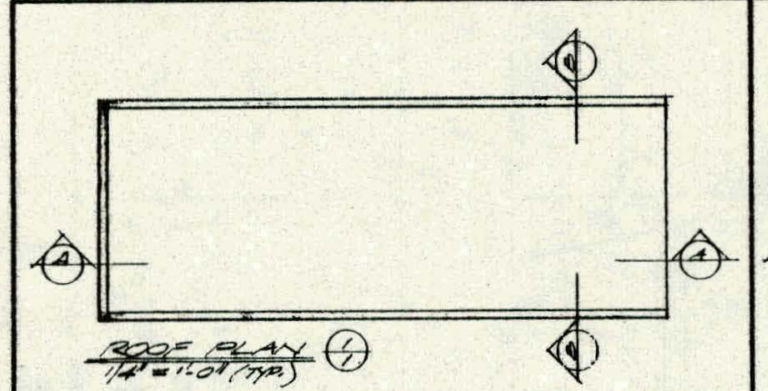

1

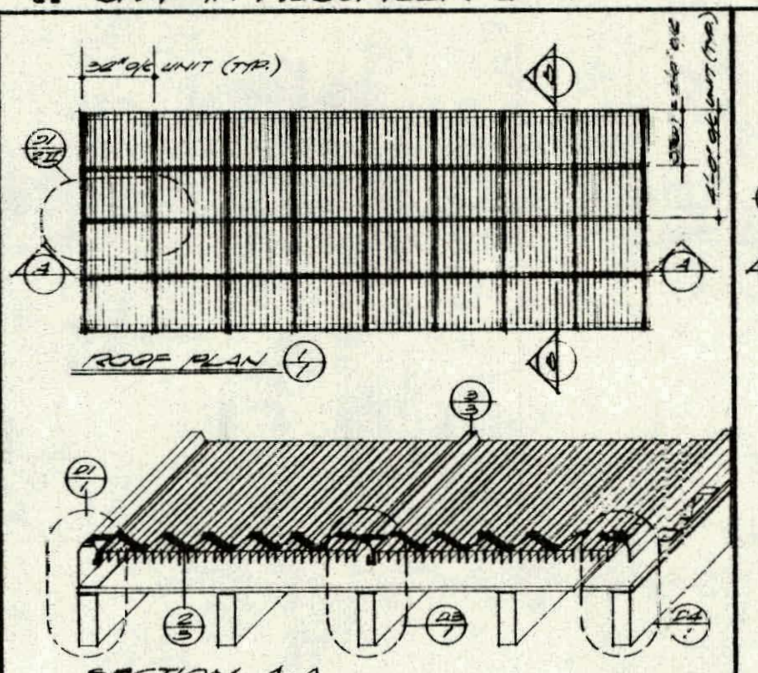

III GLAZING ON FASCIAS

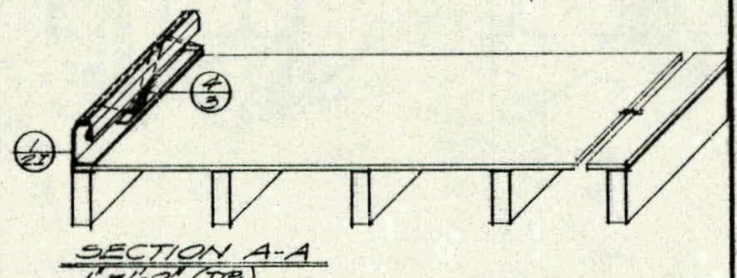
section $4-4$
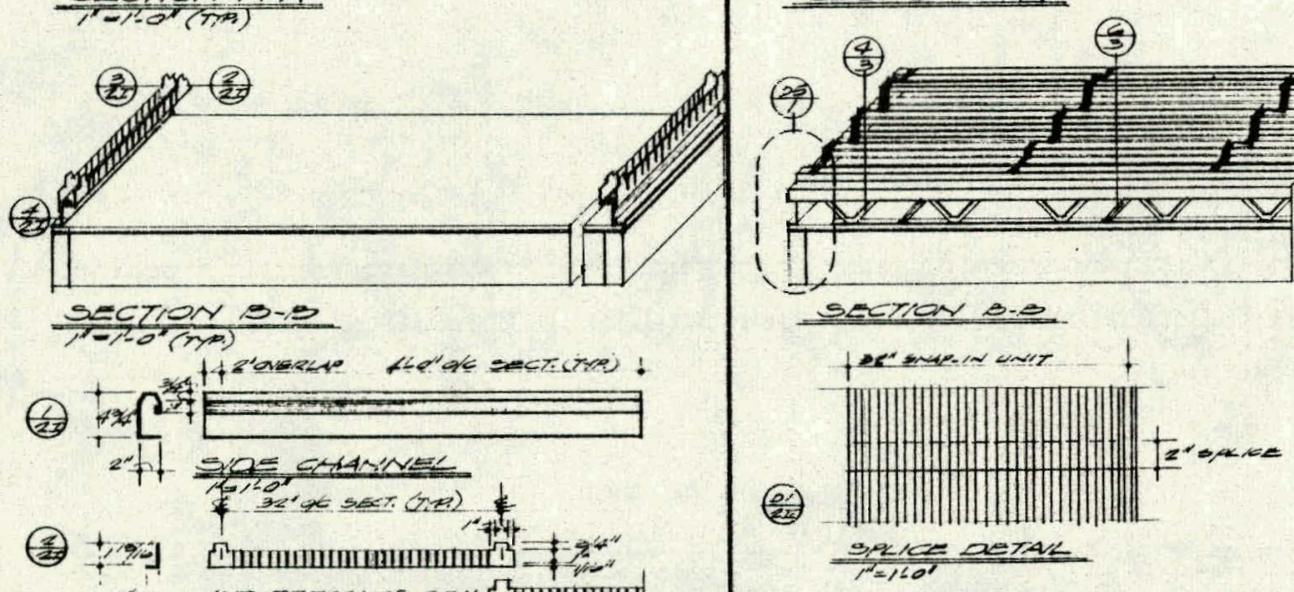

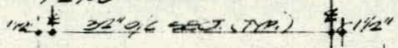

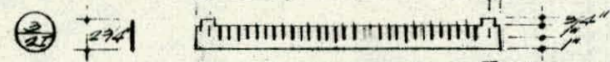

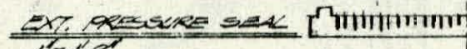

(7)

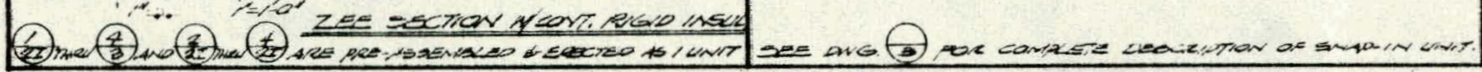

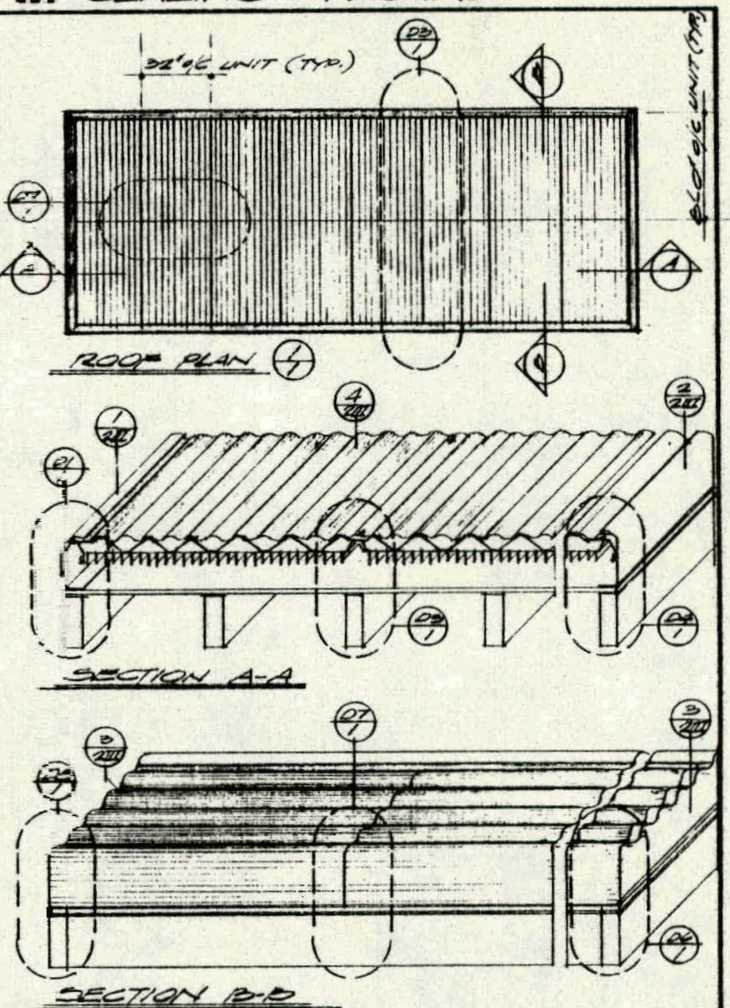
section pere

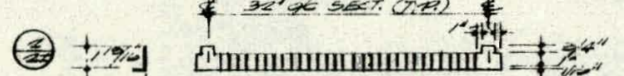

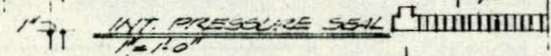
(2)

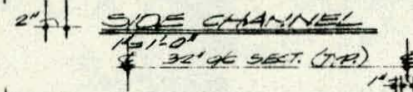

Figure 2. Scheme I, Drawing 2 Construction Sequence

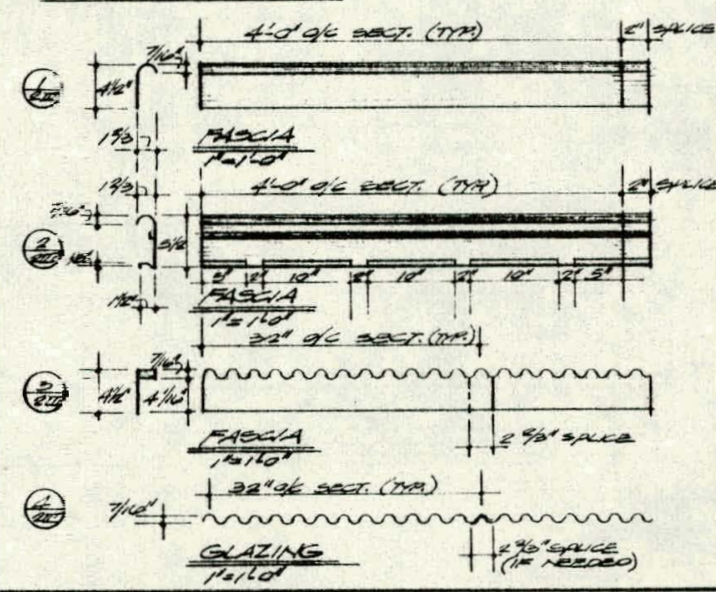

-1 गारम.? (2) 


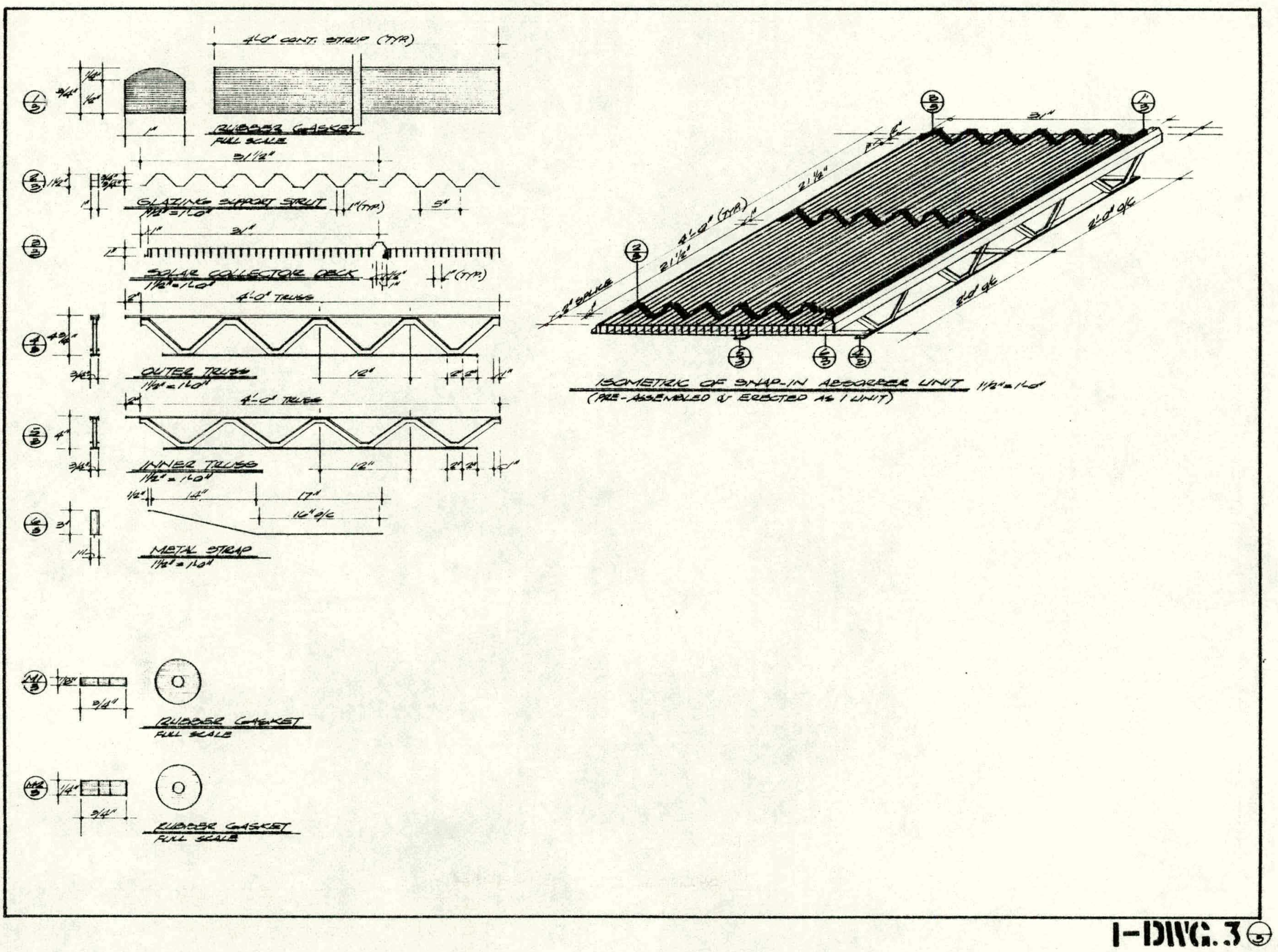

Figure 3. Scheme I, Drawing 3 Snap-In Absorber Unit 


\section{THIS PAGE}

\section{WAS INTENTIONALLY \\ LEFT BLANK}




\section{DESIGN SCHEME II}

\section{A. Construction Sequence Description}

The philosophy behind this design is to construct a framework onto which a continuous roll of absorber plate material can be applied. The glazing goes on over this, with provision for maintaining a spacing between the absorber plate and the glazing. With some attention to the sides and ends, this is all we need to make a solar collector. Complications do arise when we address the problem of air leakage from the collector and rain leakage into it; the present design is an attempt to deal with those problems.

It is assumed in this design that the collector will be applied to a plane surface of plywood. Holes in the plywood for supply and return air will have been cut before construction of the collector begins.

Drawing 1 shows section views of the collector together with certain details. Drawings 2 and 3 show the construction sequence.

The first step in construction is to nail to the roof deck a rectangular structure of zees and channels which defines the boundary of the collector. (See Drawing 2, Panel I.) The channels form the sides of the collector, perpendicular to the roof beam, while the zees form the ends, parallel to the roof beam. Next, open-web trusses are placed on the roof parallel to the side channels and perpendicular to the roof beam (Drawing 2, Panel II). The spacing between trusses is $16 \mathrm{in.}$ on centers. Over the ends of the trusses which extend over the end zees, box-section truss supports are slipped, through which the truss ends will be screwed onto the end zees after installing the glazing support struts (see below). Splicing of one truss section to another within the collector area is accomplished by means 
of a snap-on arrangement

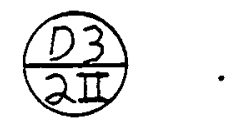

The third step is to snap into place the absorber plate hangers (Drawing 2, Panel III). Notches in the trusses guide the installer in the proper spacing (24 in on centers) of the absorber plate hangers, while the inverted U's in the absorber plate hangers act as a guide in the spacing of the trusses. At this point the trusses can be nalled to the deck, and the resulting framework is ready to receive the absorber plate.

The absorber plate (Drawing 3, Panel IV) is seen as being transported to the construction site in a roll 50 in wide to give four ft of free width plus 2 in. of overlap. The length of the roll, and therefore the amount of roof surface that can be covered in one piece, is determined by the weight of $40 \mathrm{lb}$ for any single piece which needs to be hoisted to the roof. The shape of the absorber plate is best seen in , and enlarged in (D) through D The purpose of the vees is to facilitate heat transfer, giving a needed $3: 1$ ratio of absorber plate area to roof area. Every 16 in. the pattern of vees is relieved by a rectangular gap which enables the absorber plate to fit over the trusses.

After the absorber plate is down, glazing support struts (Drawing 3, Panel V) are applied directly over the absorber plate hangers. The glazing support struts, where they pass over the trusses, are screwed to the trusses with self-tapping screws. Each of these screws will pass through, successively, a glazing support strut, the absorber plate, an absorber plate hanger, and an open-wab truss.

Plastic inserts are factory-pressed into holes in the glazing support struts. The glazing (Drawing 3, Panel VI) is now rolled out onto this array of plastic inserts and screwed to the inserts. Glazing 
material is now sold in rolls up to $50 \mathrm{ft}$ long and $5 \mathrm{ft}$ wide. In this application, we want the strips of glazing to be 51 in. wide, to allow for $4 \mathrm{ft}$ of. free width and 3 in. of overlap.

Some consideration needs to be given to how the glazing is to be applied to the structure, once the absorber plate is in place. The absorber plate will not support a man's weight, and even a single truss, if optimized in strength for its function as part of the solar collector, might not withstand the point load of a person stepping on it. A ladder, fitted with a transverse beam spanning several trusses, might solve the problem. After all of the absorber plate has been installed and the glazing support struts screwed down on top of it, the glazing strips could be installed starting either at the top or the bottom, as long as care is taken that lower sheets are overlapped by those above.

The final step in the installation is the application of the end fascia $\left(\frac{105}{12}\right)$. and 3 ) and the side fascia (

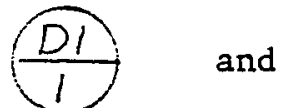
can be slid in behind these fascias, as is shown in fascia.

\section{B. Parts Glossary}

The parts are described in the order in which they are applied during construction. Below is an alphabetical parts list, followed by the number of the article describing the part in this glossary. 


\section{PART}

Absorber Plate

Channel, Side

Fascia, End

Fascia, Side

Glazing

Hanger, Absorber Plate

Splicè, Corner

Strip, Rubber

Strut, Glazing Support

Truss, Open Web

Truss Support, Box Section

Zee, End
ARTICLE NO. IN GLOSSARY

7

1

12

11

10

6

了

9

8

4

5

2

1. Side Channel $\frac{1}{2 I}$

Dimensions $4 \mathrm{ft} \times 41 / 2 \mathrm{in.}$ Might also be produced in $8 \mathrm{ft}$ or longer sections. Top flange $1 \mathrm{in}$, bottom flange 2 in. to facilitate nailing of channel to root deck. Nominal thickness 0.060 in. Every 16 in there is a $1 / 2$ in slot in the top flange of the side channel to accomodate the absorberplate hanger. Rigid insulation is bonded to the inside of channel as part of the manufacturing process.

2. End Zee $\frac{155}{2 I}$

Dimensions $4 \mathrm{ft} \times 3 \mathrm{in}$. Should also be available in 64 in. and 80 in. sections to allow for roof widths of any multiple of 16 in. Top flange 1 in., bottom flange 1 in. Nominal thickness 0.060 in. Interior and exterior pressure sedis and $\frac{3}{2 I}$ are notched to receive the vees and the 
absorber plate. These are attached to the zee during the manufacturing process. Their dimensions are identical so that both can be cut to the same shape. . The interior pressure seal must be bent longitudinally in order to be applied to the inside of the zee. A strip of insulation laid between the pressure-seal strips to inhibit air flow. The pressureseal strips are 2 in. longer than the zees to allow overlap on each side; their nominal thickness is $0.016 \mathrm{in}$. The ends of the trusses are screwed to the zees through box-section truss supports

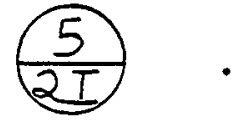

3. Corner Splice

This is a small L-shaped piece of metal, $17 / 8$ in high and with each arm of the I 2 in. long. Nominal thickness is 0.060 in. It is screwed to the side zee and the end channel at each corner to provide rigidity to the structure.

4. Open-Web Truss (Drawing 1, Section B-B; Drawing 2, Pane I II)

Dimensions 49 in, $\times 41 / 2$ in. $\times 1$ in. Might also be produced in $8 \mathrm{ft}$ or longer sections. Nominal thickness of horizontal strips 0.016 in, diagonal webbing $0.054 \mathrm{in.}$ Every $16 \mathrm{in}$, the top of the truss is notched $\frac{12}{2 \pi}$ to receive the absorber-plate hangers. The ends of the truss are shaped (DI) so that one will slide into the other. An upward-turned tab on the male end snaps into a hole in the female end, providing positive locking of one truss section to the next. Either end of a truss section may be screwed to an end zee through a box-section

5. Box Section Truss Support

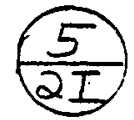
(5)

This is an extruded piece with a hole drilled through it. The slot holds it in place under the truss end while the absorber plate and glazing support struts are set in place, after which it acts as a spacer in the 
screwing down of the above parts to the top flange of the end zee.

6. Absorber Plate Hanger (Drawing 1, Section A-A; Drawing 2, Panel III)

49 in. length shown; may be produced in longer lengths. Lateral dimensions are as shown in (III) Nominal thickness 0.032 in. Every 16 in the horizontal section of the hanger rises $11 / 2$ in. to fit over the trusses; and there is a break in the section which hangs down obliquely.

7. Absorber Plate (Drawing 1, Section A-A; Drawing 3, Panel IV)

W1dth 50 in. Length - as long as possible without exceeding $40 \mathrm{lb}$ weight limit. Nominal thickness 0.005 in. if aluminum, 0.012 in. if steel. Shaped as shown in diagram, with 1 in. deep vees occuring every 1 in. to facilitate heat transfer. Every 16 in. the absorber plate rises $1 / 2$ in. above its general level to enable it to pass over the trusses.

8. Glazing Support Strut (Drawing 1, Section A-A; Drawing 3, Panel V) Dimensions 49 in. $\times 1$ 1/4 in. $x 1 / 2$ in. May be produced in longer lengths. Nominal thickness 0.032 in. Every 16 in. there is a 1 in. vertical gap in the vertical flanges of the channel-shaped strut to allow it to pass uver the trusses.

9. Rubber Strip $\frac{2}{3 \vec{V}}$

This $3 / 4$ in. wide by $1 / 4$ in. thick strip runs along the top of the side channels. The strip is adhesive-backed to inhibit shifting before it is screwed into place. A $1 / 8$ in. deep groove along the top of the rubber strip allows screw heads to finish below the top of the strip. After passing through the strip, the screw passes through, successively, a glazing support strut, the absorber plate, and absorber plate hanger, and the side channel

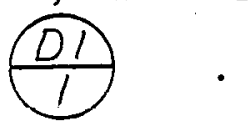

10. Glazing (Drawing 3, Panel VI! . .

The glazing is to be a fiberglass-impregnated plastic such as "Kaliall" 
or "Filon". It is currently manufactured in $5 \mathrm{ft} \times 50 \mathrm{ft}$ rolls. We will assume a width of 51 in and a length equal to the horizontal dimension of the collector, which for our design example is $32 \mathrm{ft}$. Thickness is $0.040 \mathrm{in}$.

11. Side Fascia $\frac{2}{3 \sqrt{1}}$

Dimensions 51 in. $\times 33 / 4$ in. $\times 1$ in. Nominal thickness 0.016 in. Applied to side channel with screws, flashed behind if necessary

12. End Fascia $\frac{3}{3 \pi}$

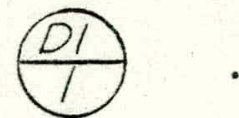

Dimensions 51 in. $\times 4$ in. $\times 11 / 4$ in. Nominal thickness 0.016 in. Applied to end zee with screws through $1 / 2$ in spacer, flashed behind

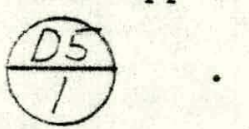

\section{Materials Specifications and Design Options}

In this design both aluminum and steel should be considered as candidate primary fabrication materials. The design is drawn with flat rather than with corrugated glazing (for a description of corrugated glazing see Design Scheme 1). The use of corrugated glazing is an alternative option in this design. All screws should be self-tapping, with integral plastic inserts under the heads to provide weathersealing. 
SC:HIEME?
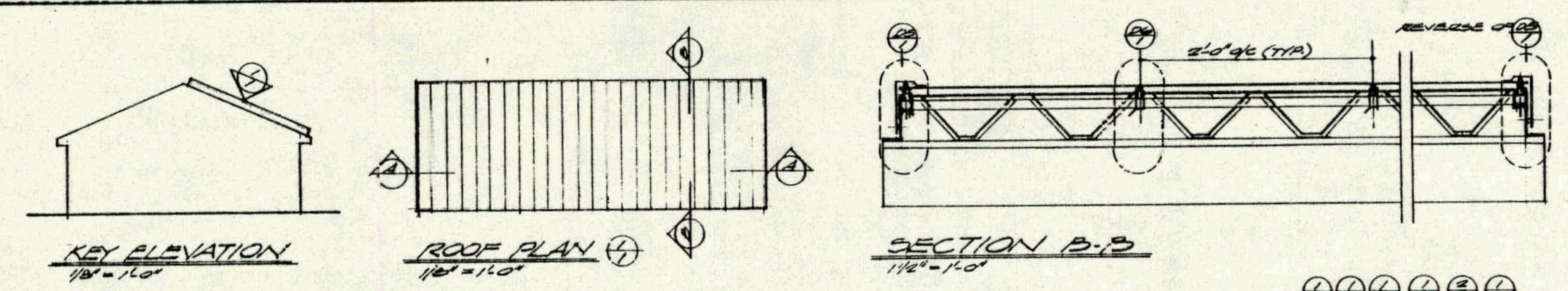

SECTION B-S

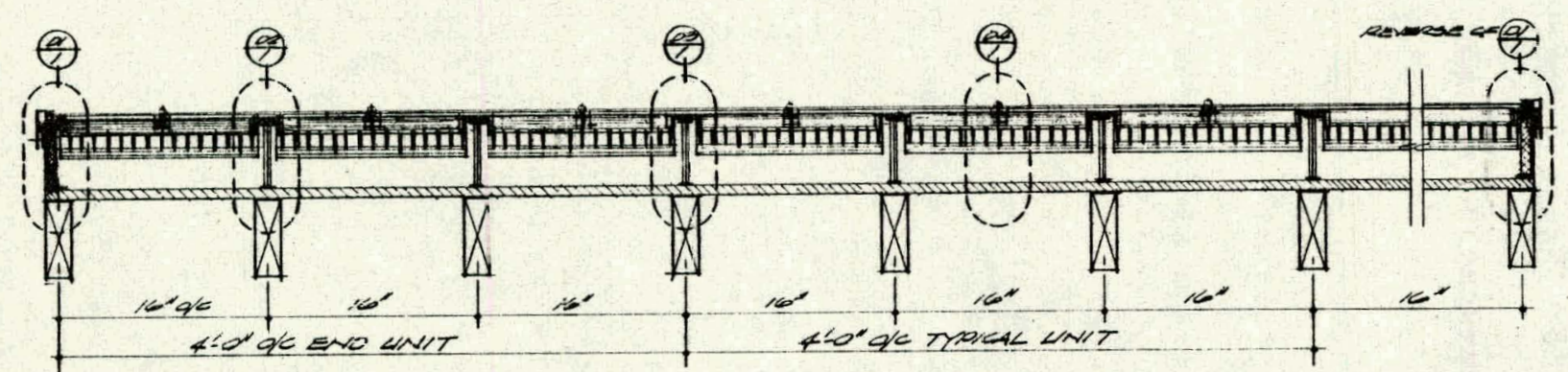
SECTION A-A
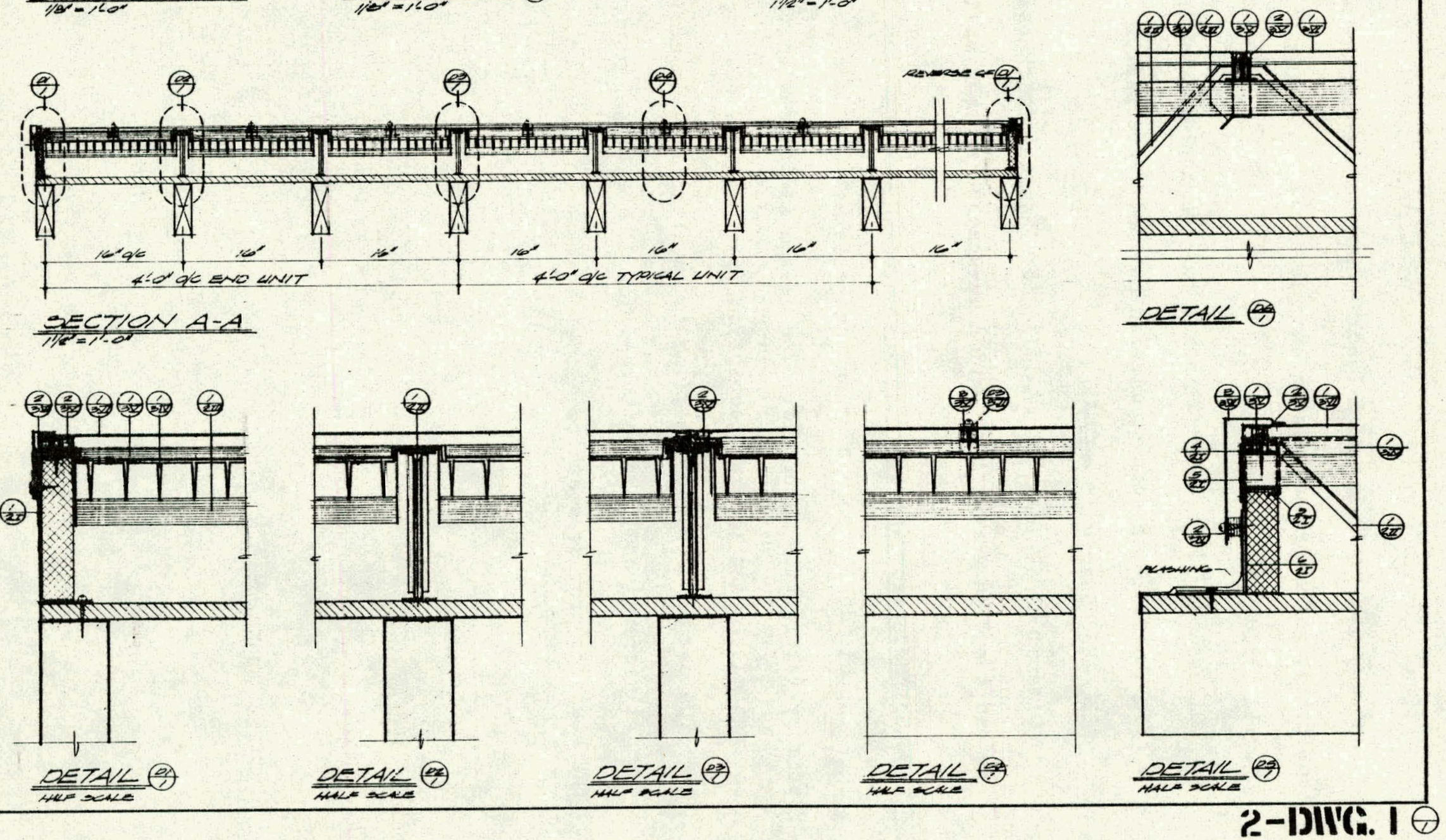

Figure 4. Scheme II, Drawing 1 Section Views and Jetails 
II OREN WES VOISTS (TRUSS)

III ABSORBER PLATE HANEERS
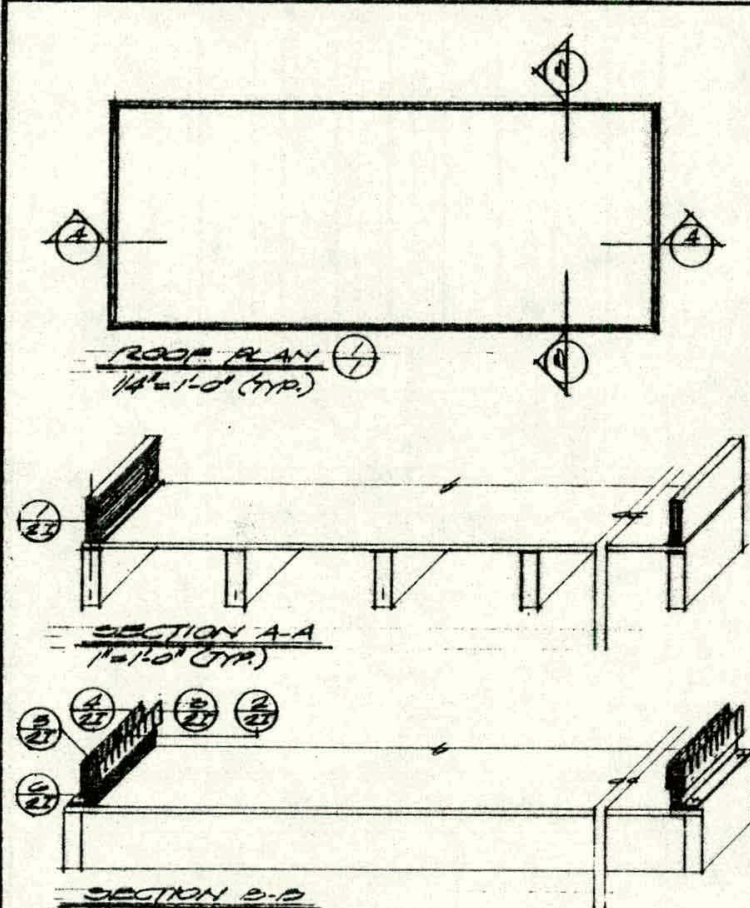

$$
\text { stropreas }
$$
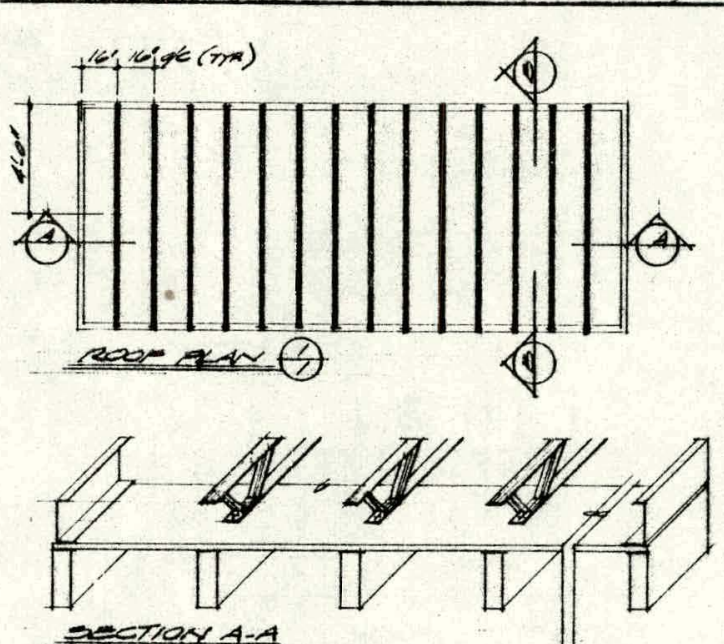

$$
\text { antrox } 4-4
$$

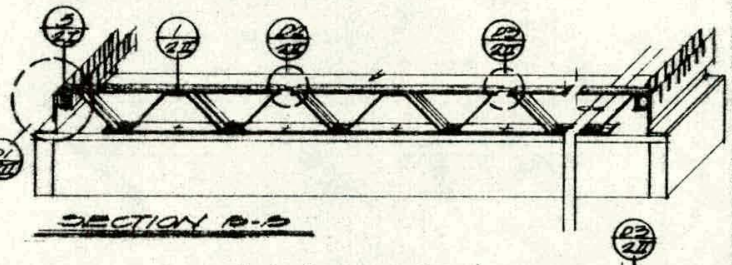

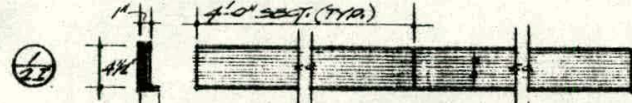

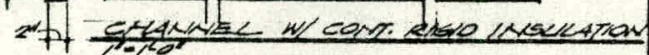

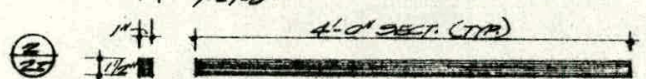

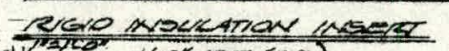

(3)

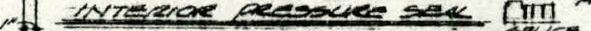

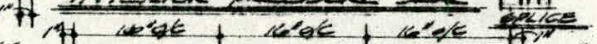

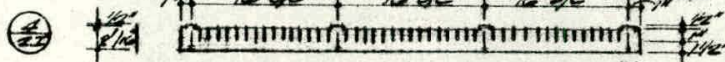
experiar aretexuer a $\mathrm{mm}$

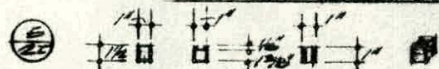

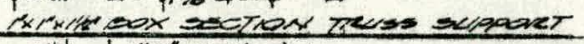

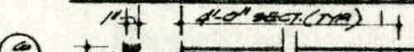

(2) $\mid \frac{1}{11}$ -

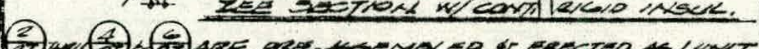

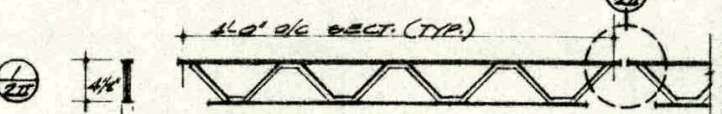
"At renses

"

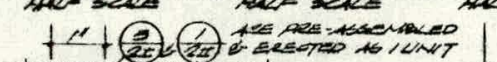

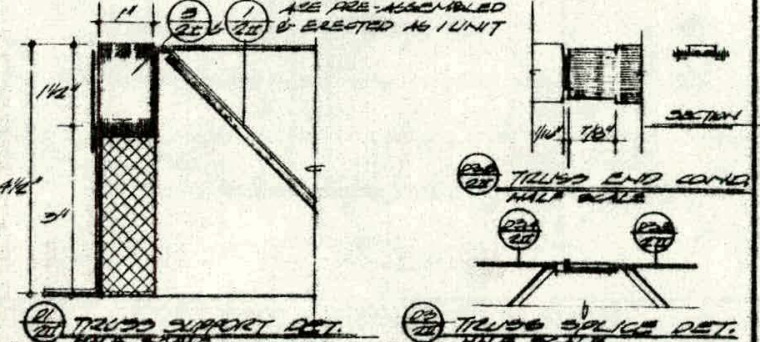

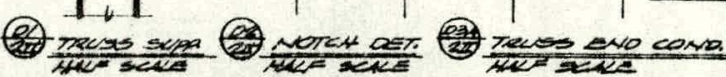
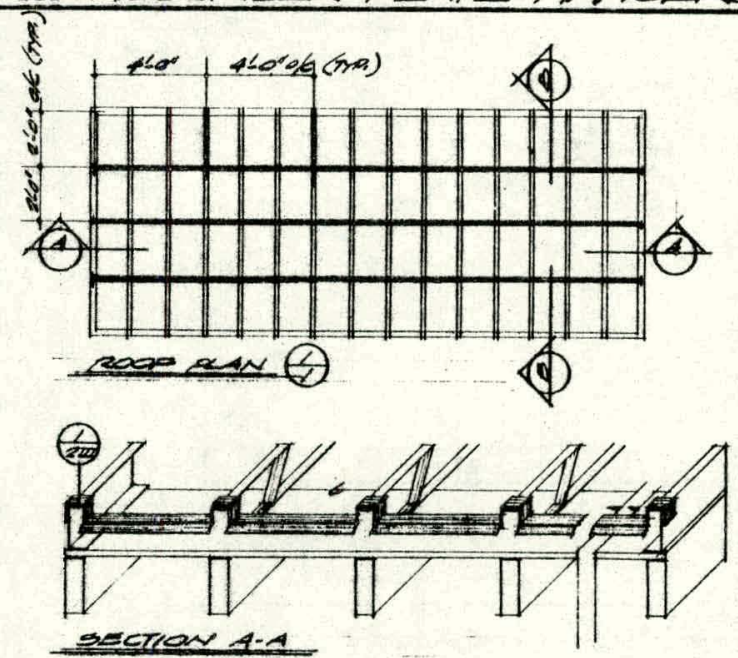

section $4-4$

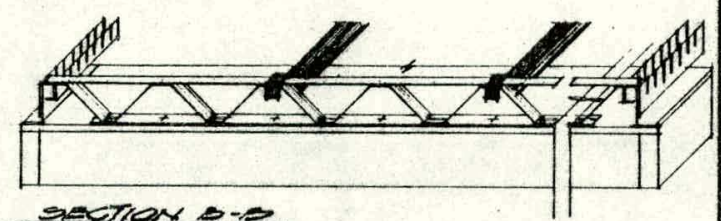

siectiax -2

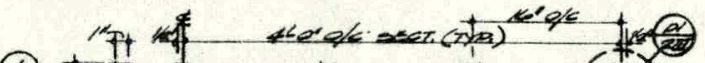
(2) 你或 $+<+$

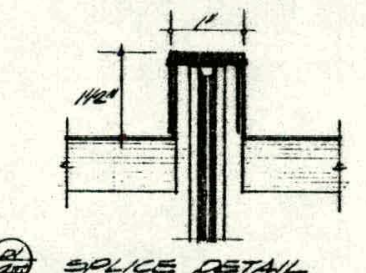

(2) SOLCE DTIAL 
IV ASSORBER PLATE

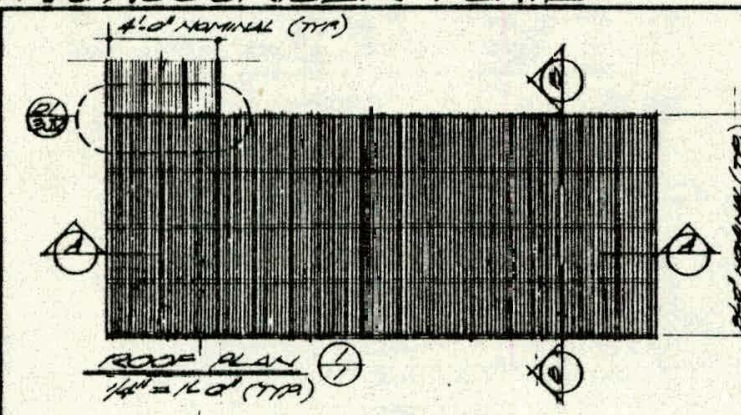

(20)

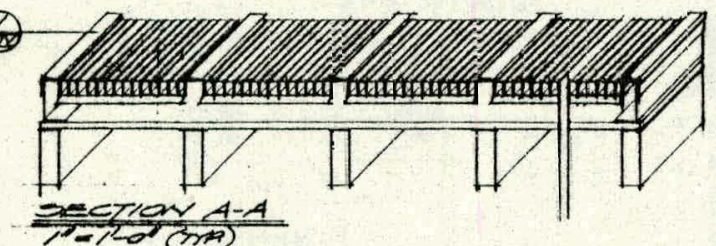

mextion $4-4$

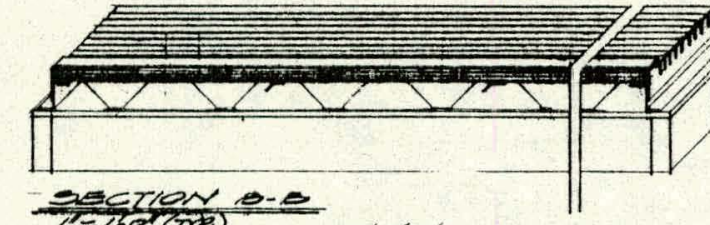

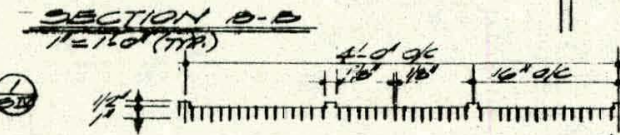

(2)

(62) asoperer ante

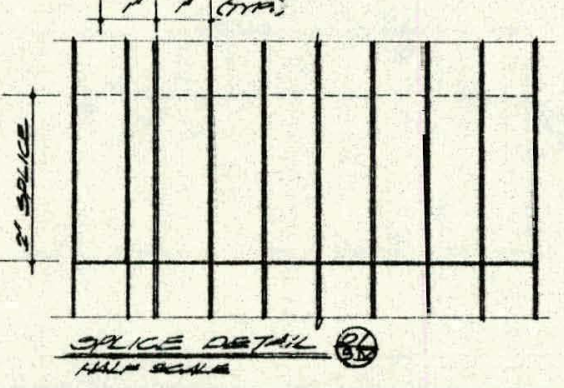

Y GLAZINE SUIPORT STRUT
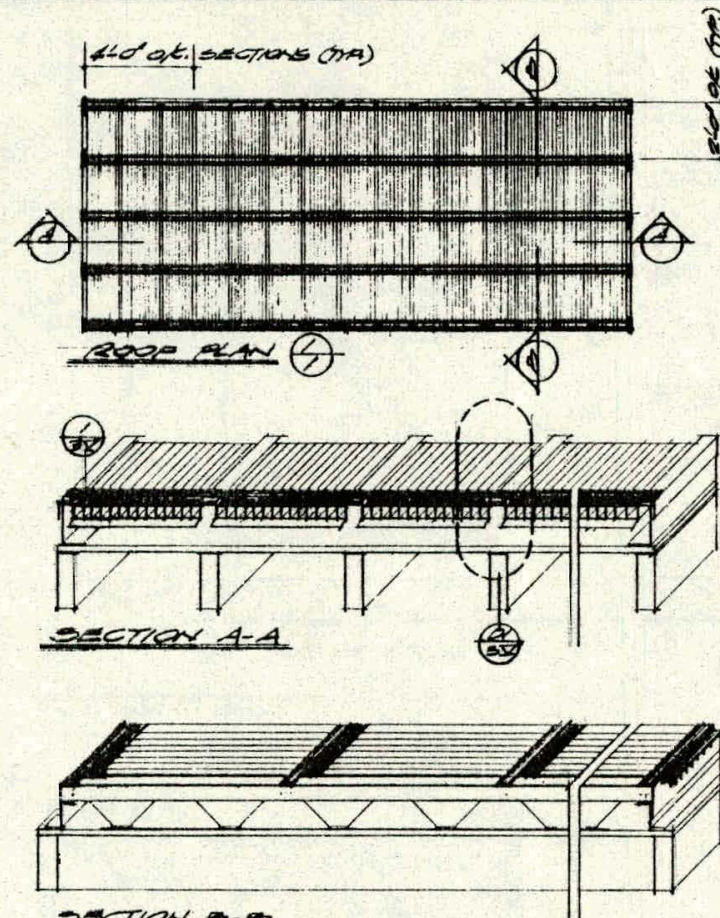

entren

(2),

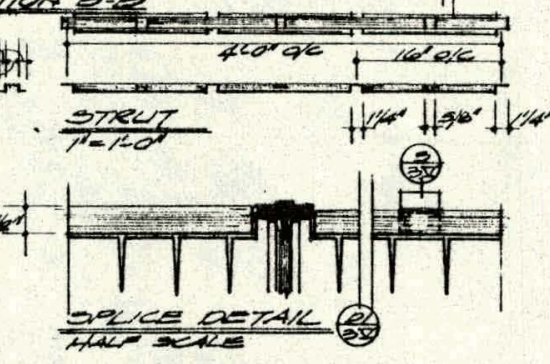

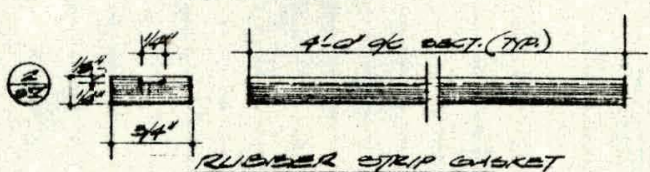
ruener spere arsicet

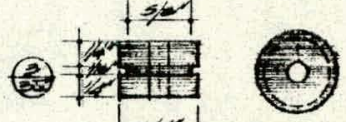

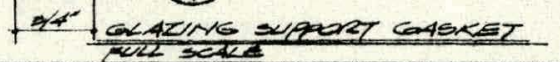

VI gLaZME o fascias

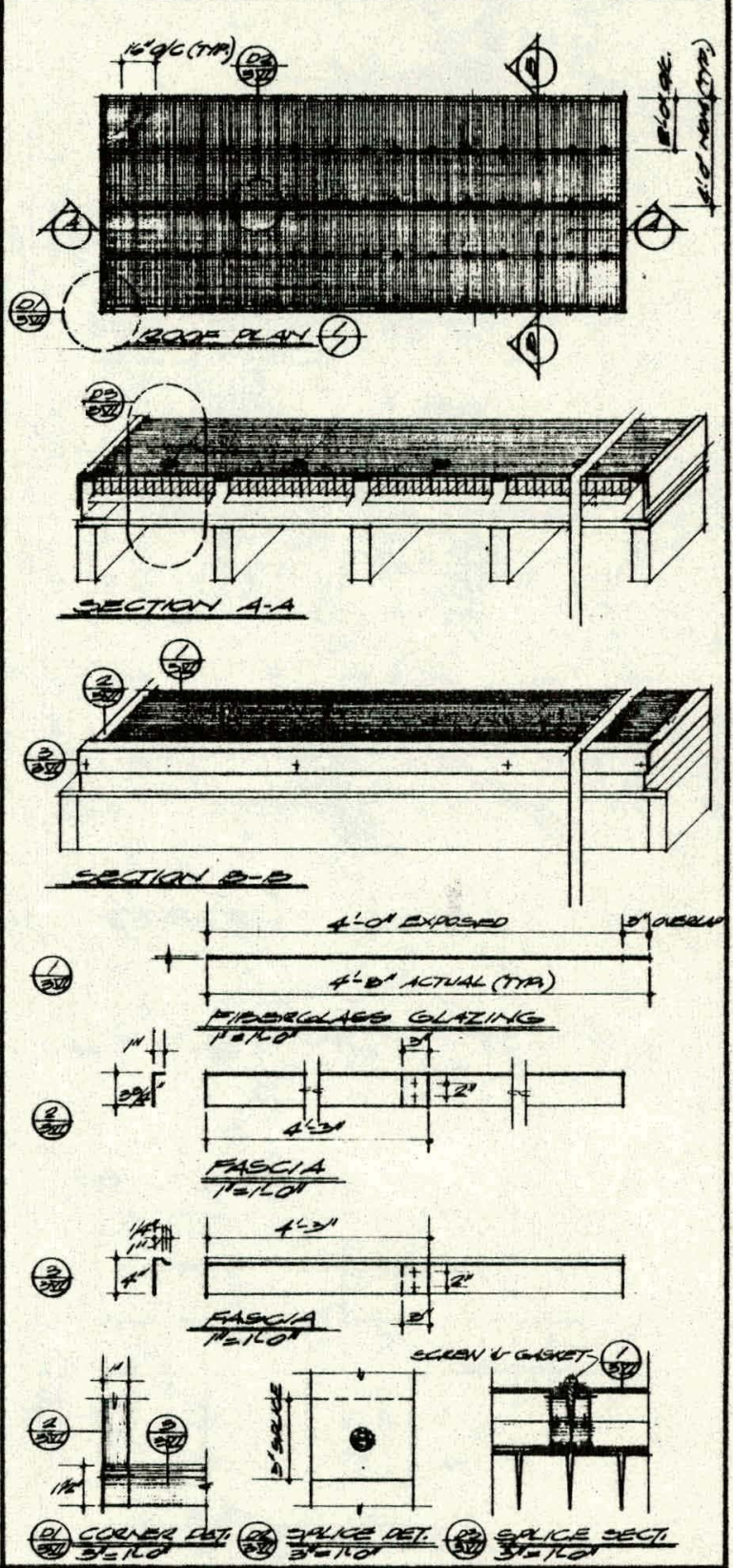

?-IगIR. 30

Figure 6. Scheme II, Drawing 3 Construction Sequence 


\section{DES IGN SCHEME III}

\section{A. Construction Sequence Description}

This design was motivated by considerations similar to those which produced Design Scheme II. The major new element is the use of crimping as a way of fastening those parts of the collector which lie above the absorber plate to those parts which are located below.

The use of crimping makes it unnecessary to pierce the absorber plate, thus making it a better rain barrier. We assume that some rain will penetrate the glazing, and the absorber plate must therefore provide a second line of defense against water penetration.

As in the other designs, attention is paid to the sides and ends, consideration being given to pressure sealing, rain leakage, and esthetic appearance.

It is assumed in this design that the collector will be applied to a plane surface of plywood. Holes in the plywood for supply and return air will have been cut before construction of the collector begins.

Drawing 1 shows section views of the collector together with certain details. Drawings 2 and 3 show the construction sequence.

The first step in construction is to nail to the roof deck a rectangular structure of channels and L-sections which defines the boundary of the collector. (See Drawing 2, Panel I). The channels $\frac{1}{2 I}$ form the sides of the collector, perpendicular to the roof beam, while the L-sections form the ends, parallel to the roof beam. Next, open-web trusses are placed on the roof parallel to the side channels and perpendicular to the roof beam. To each of these trusses, and to the side channels 
as well, clamp plates $\frac{2}{2 I}$ are attached at 24 in. intervals. The purpose of the clamp plates is to provide a substructure onto which the upper portion of the collector can be fastened by crimping. Also attached to the trusses at 24 in. intervals, beneath the clamp plates, are hanger supports (3) - Their purpose is to provide a fastening point for the absorber plate hangers. The assembly of the trusses, clamp plates, and hanger supports is to be a factory operation, the units containing the above pieces arriving at the site fully assembled.

The absorber plate hangers (Drawing 2, Panel II) are installed next. Their purpose is to support the absorber plate. Two slits in each end of a hanger allow it to be slid onto the hanger supports $\frac{3}{2 I}$. The bends in the hanger support provide a positive hold on the absorber plate hangers. After the absorber plate hangers are in place, the trusses can be nailed down permanently to the roof.

The next construction step is to place the absorber plate (Drawing 3, Panel III) down on the trusses. It is seen as being transported to the construction site in a roll, 50 in.wide to give $4 \mathrm{ft}$ of free width plus 2 in. of overlap. The length of the roll, and therefore the amount of roof surface that can be covered in one piece, is determined by the weight limit of 40 lb for any single piece which needs to be hoisted to the roof. The shape of the absorber plate is best seen in and in Section A-A of Drawing 1. The purpose of the vees is to facilitate heat transfer, giving a reeded 3:1 ratio of absorber plate area to roof area, Every 16 in. the pattern of vees is relieved by a gap which allows the absorber plate to fit over the trusses. 
After the absorber plate is down, it is crimped to the clamp plates

(2I by crimped plates $\frac{1}{3 I}$. A crimping tool is used to fold in. the flanges of these crimped plates. Details $\frac{D}{1}$ through (1) show how the absorber plate is held to the clamp plates on the trusses by the crimped plates above it.

Each of the crimped plates has two split posts protruding upward from it. Pipes and glazing supports 3 are slipped over these posts, after which the split ends are bent downward over the ends of the glazing support to provide a secure fastening. At the end channels, closed end pipe pieces. $\frac{2}{3 V}$ are used. These provide two additional inches of pipe, but more importantly, a closed end onto which the side fascia can be attached.

The corrugated glazing is now screwed onto the glazing supports (Drawing 3, Panel VI). It will be applied in strips, 51 in.wide and as long as the roof. Each strip will overlap the one below it by 3 in, giving 48 in. of free width.

Some consideration needs to be given to how the glazing is to be applied to the structure, once the absorber plate is in place. The absorber plate will not support a man's weight, and even a single truss, if optimized in strength for its function as part of the solar collector, might not withstand the point load of a person stepping on it. A ladder, fitted with a transverse beam spanning several trusses, might solve the problem. After all of the absorber plate has been installed and the crimped plates, pipes, and glazing supports put into place, the glazing strips could be installed starting either at the top or the bottom, as long as care is taken that lower sheets are overlapped by those above. 
The final step in the installation is the application of the side fascias and and $)$ and end fascias $\left(\frac{21}{15}\right.$, The end fascias are screwed to the end L-pieces through for rain which may have gotten to the absorber plate through imperfect seals in the glazing, and they also allow a small amount of air flow between the glazing and the absorber plate to kepp the temperature from rising luu lilgh under stagnation conditions. At the high end $\frac{06}{1}$ the fascia goes over the glazing, while at the low end the fascia goes under the glazing, to facilitate rain runoff.

The side fascias ( $\frac{2}{3 V}$ and as flashing as we11. They are screwed into the closed end pipe pieces $\frac{2}{2}$ which form the ends of each terminal section of pipe on each side of the collector (Section A-A of Drawing 3, Panel V)。

\section{B. Parts Glossary}

The parts are described in the order in which they are applied during construction. Below is an alphhetical parto liat, followed by the number of the article describing the part in the glossary.

\section{PART}

Absorber Plate

Channel, Side, with Clamp Plates

Fascia, End

Fascia, Side
ARTICLE NO. IN GLOSSARY 
Glazing

Hanger, Absorber Plate. $\quad 4$

L-Section, End 1

Pipe, Hollow 7

Pipe Piece, Closed End 8

Plate, Crimped $\quad 6$

Support, Glazing 9

Truss 3

1. End L-Section $\frac{5}{2 I}$

Overall dimensions 48 in. $\times 4$ in, with 1 in flange. Nominal thickness 0.064 in. Top edge of section notched to receive vees in absorber plate.

2. Side Channel with Clamp Plates $\frac{T}{2 I}$

Overall dimensions 48 in. $\times 4$ in. Top flange 1 in, bottom flange 2 in. Clamp plates $31 / 2$ in. or $33 / 4$ in. wide. Hanger supports extend $21 / 2$ in on inboard side of the channel. Nominal thickness of channel 0.064 in. For description of Clamp Plates and Hanger Supports which form part of the side channel unit, see Article 3, Truss.

3. Truss $\frac{4}{2 I}$

Overall dimensions $491 / 2$ in $\times 37 / 8$ in. Horizontal strips and diagonal webbing 1 in wide. Clamp plates $31 / 2$ in or $33 / 4$ in. wide. Hanger supports extend 6 in-perpendicular to the truss. Nominal thickness of horizontal strips 0.016 in, diagonal webbing 0.060 in. Nominal thickness of clamp plates 0.100 in. Hanger supports to be of spring steel of sufficient gauge to support absorber plate and live load. 
The clamp plate on one end of a truss is notched, and is slightly narrower than that on the other end, so that truss sections can be spliced together. The purpose of the notch is to make room for the end of the horizontal strip on the other truss as the two trusses are spliced together.

The hanger support 3 is shaped so that it can be forced upward through the first hole in an absorber plate hanger $\frac{1}{2 I}$ and then downward through the second hole, making a tight connection.

\section{Absorber Plate Hanger $\frac{1}{2 \pi}$}

Overall dimensions $143 / 4$ in. $\times 1$ in. $\times 1$ in. Nominal thickness 0.032 in. Iwo slits near each end to receive hanger supports $\left(\frac{3}{2 T}\right)$.

5. Absorber Plate (Drawing 1, Section A-A; Drawing 2, Panel III)

Width 51 in. Length - as long as possible without exceeding $40 \mathrm{lb}$ weight limit. Nominal thickness $0.012 \mathrm{in}$.

Shaped as shown in drawing, with 1 in. deep vees occuring every 1 in to facilitate heat transfer. Every 16 in. the absorber plate has a vee-free section to allow it to pass over the clamp plates on the trusses.

6. Crimped P1ate $\frac{1}{3 \pm}$

Overall dimensions 2 in. $x 3$ in.with 1 in, flanges extending below and 1 1n splie posts rising above. Nominal thickness 0.120 in.

7. Hollow Pipe $\frac{1}{3 \bar{V}}$

Overall dimensions 48 in. $\times 3 / 4$ in. O.D. Nominal wall thickness 0.016 in. A hole is drilled 1 1/2 1n. Erom each end to allow the pipe to fit onto split posts of the crimped plates.

8. Closed End Pipe Piece $\frac{2}{3 \bar{D}}$

Overall dimensions $21 / 2$ in. $\times 3 / 4$ in. $0 . D$. Wall Thickness 0.060 in. One 
end tapers to fit inside end of pipe section. The other end is closed off so that the side fascia 2 can be screwed into it. A hole drilled through. this piece allows it to be placed over a post in a crimped plate over a side channel.

\section{Glazing Support $\frac{3}{3 \sqrt{V}}$}

Overall dimensions 4 in. $\times 1$ in. $\times 1 / 2$ in. Nominal thickness 0.032 in. Holes drilled on each side of this U-shaped piece receive the split posts of the crimped plates
10. Glazing $\frac{1}{3 \sqrt{Z}}$

The glazing is to be a fiberglass-impregnated plastic such as "Kalwall" or "Filon". It is currently manufactured in $5 \mathrm{ft} \times 50 \mathrm{ft}$ rolls. We will assume a width of 51 in. and a length equal to the horizontal dimension of the collector, which for our design example is $32 \mathrm{ft}$. Thickness is 0.040 in. This design calls for corrugated glazing. The peak-to-trough height of the corrugations is $9 / 16$ in, while the lateral distance from one peak to the next is $22 / 3$ in, so that 6 full corrugation wavelengths will fit over each 16 in. width of absorber.

11. End Fascia $\frac{3}{3 \sqrt{17}}, \frac{14}{1}$, and

Overall dimensions 48 in $\times 37 / 8$ in $\times 1$ in. Nominal thickness 0.016 in. The top flange of this fascia is scalloped to fit the glazing. If this proves very costly to fabricate with sheet metal, a high-temperature injectionmolded plastic might be considered, or the fascia might have to be redesigned. The fascia is screwed to the end L-piece through spacers $\frac{5}{3 \sqrt{2}}$ and to the glazing. The screws through the glazing are placed at the peaks of the corrugations, to minimize rain leakage. 
12. Side Fascia $\frac{2}{212}$ and $\frac{D 1}{1}$

Overall dimensions 48 in. $x 47 / 8$ in. with flanges at top and bottom. Top flange fits over glazing, bottom flange acts as flashing. Nominal thickness 0.016 in. Fascia fastened with screws to ends of closed end pipe pieces.

\section{Materials Specifications and Design Options}

Because of the use of crimping in this design, the primary fabrication material will be steel. The design is drawn with corrugated glazing and part of its motivation is to allow for reduced heat transfer between the pipes and the glazing, since there is only point contact between the two. Therefore, flat glazing is not to be considered in this design.

All screws should be self-tapping, with integral plastic inserts under the heads to provide weatherproofing. 


\section{S(:HIEMIE 3}
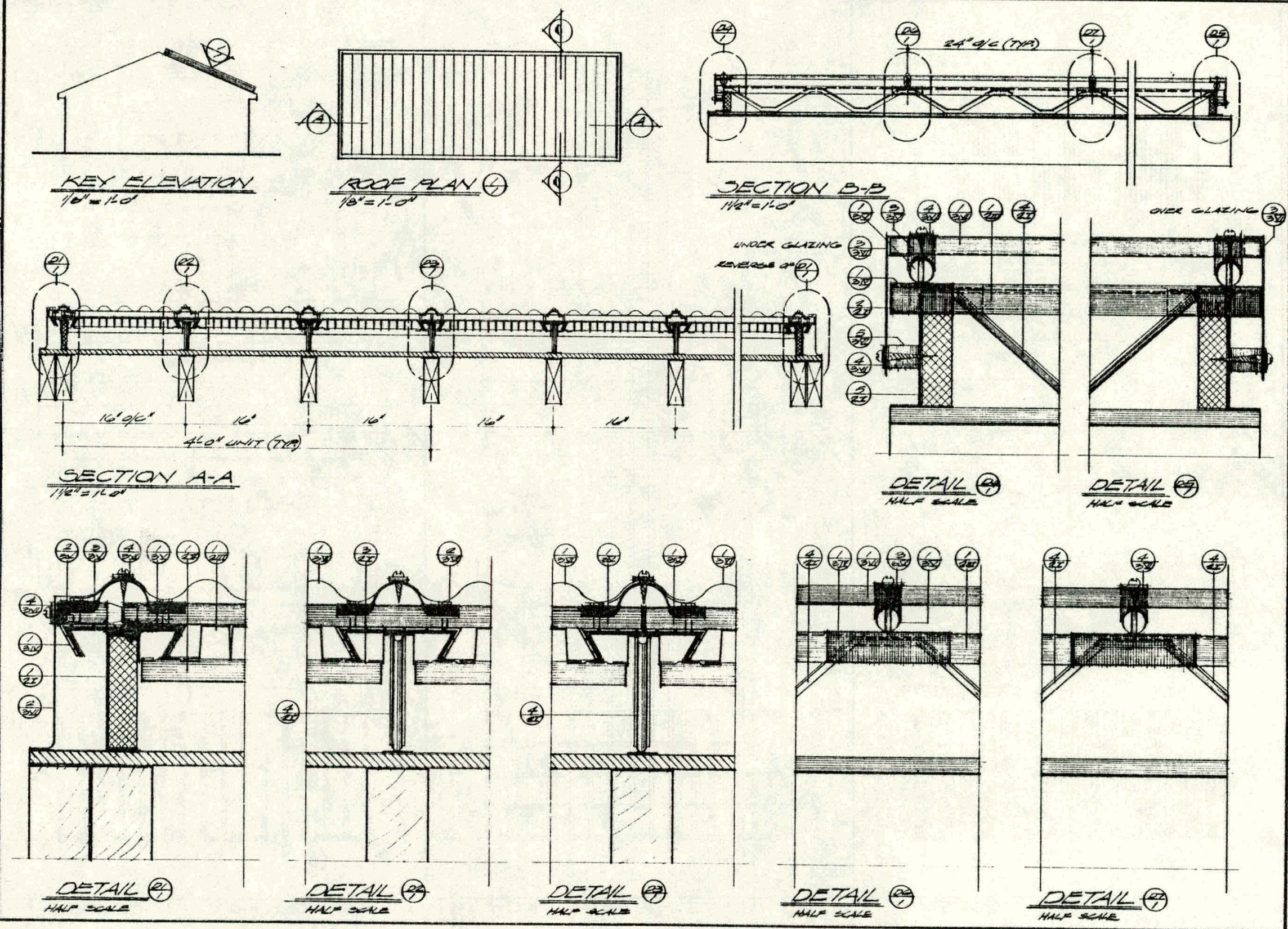

Figure 7. Scheme III, Drawing 1 Section Views and Details 
CONSTRLETIN SEQLVNCE DRAWINGS

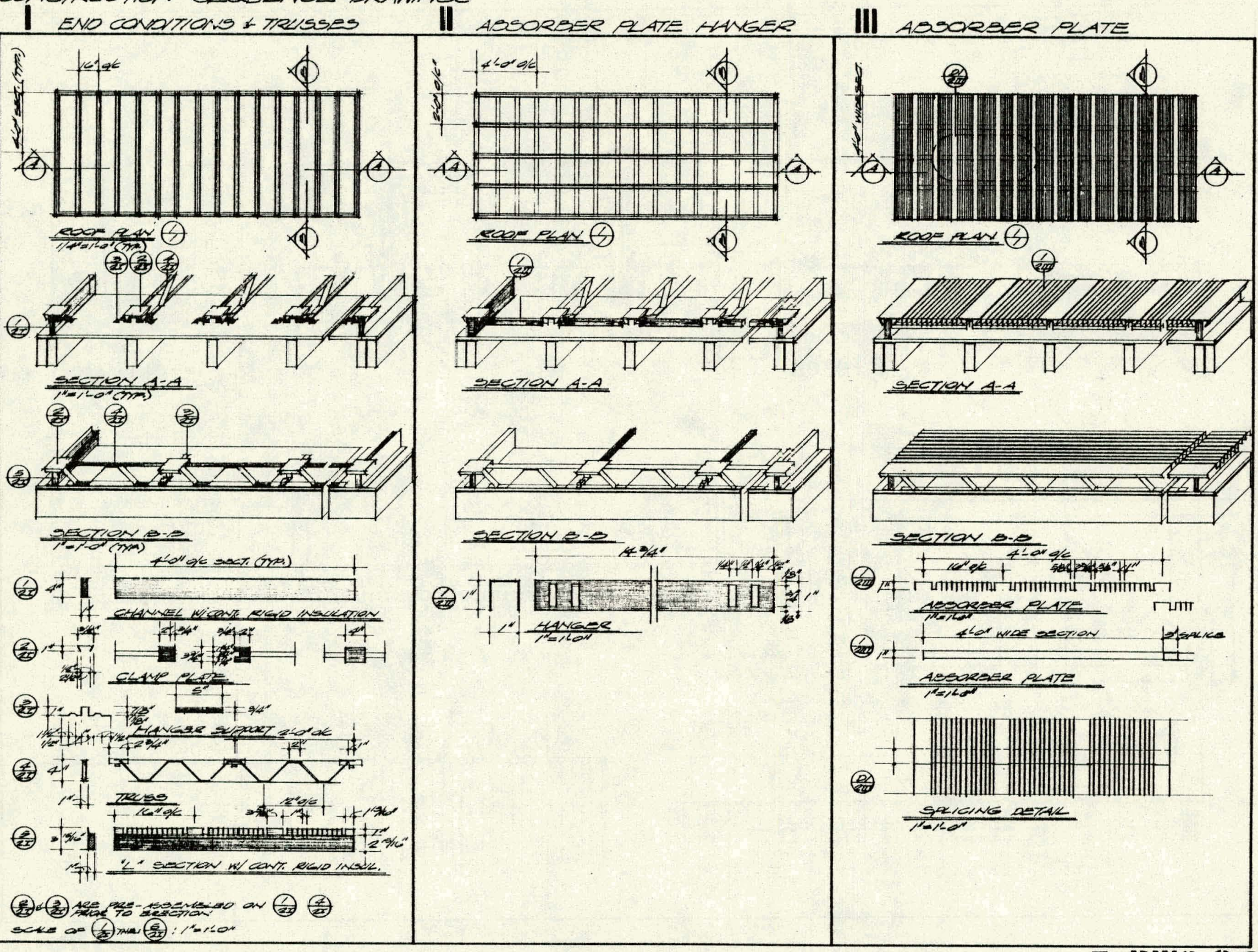


IV crmpeo rlates

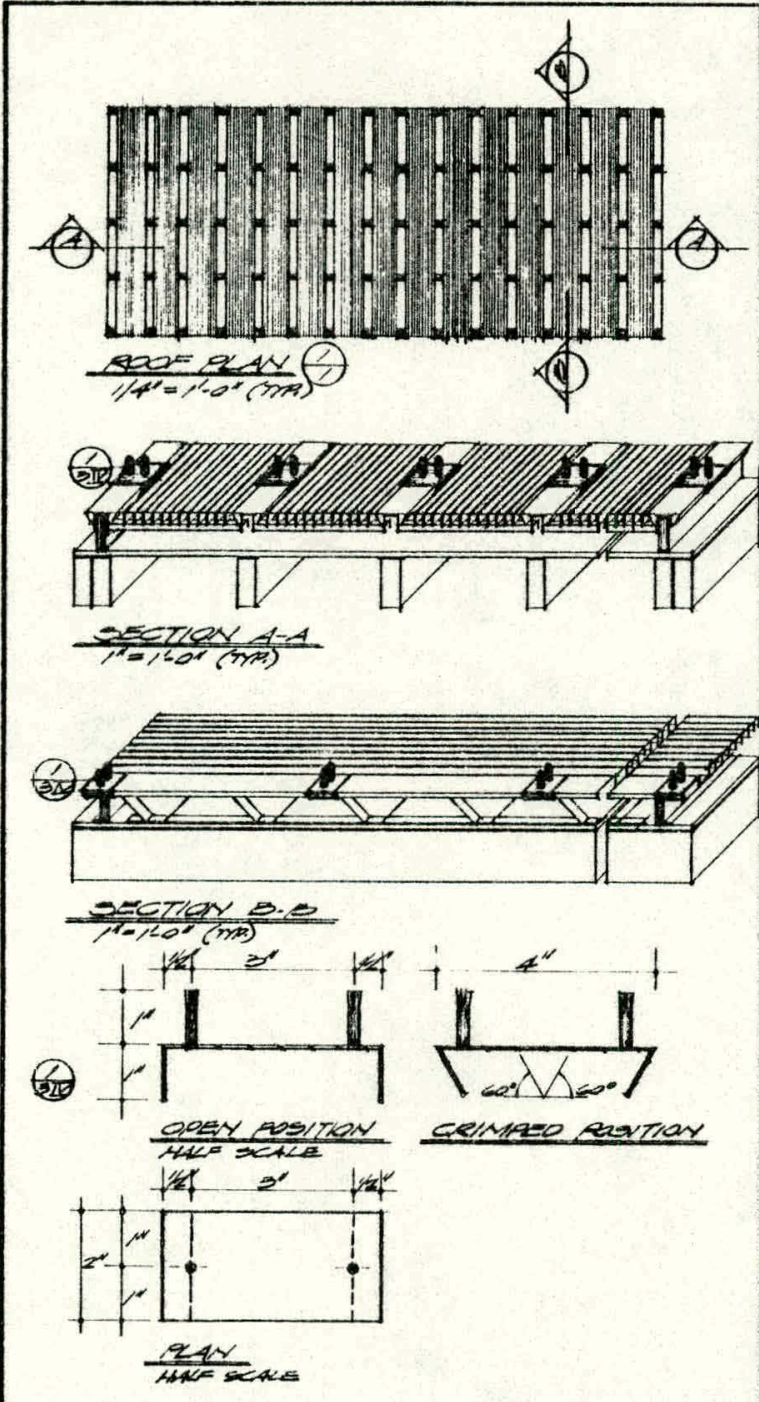

$V$ pipes w GLAZME supports

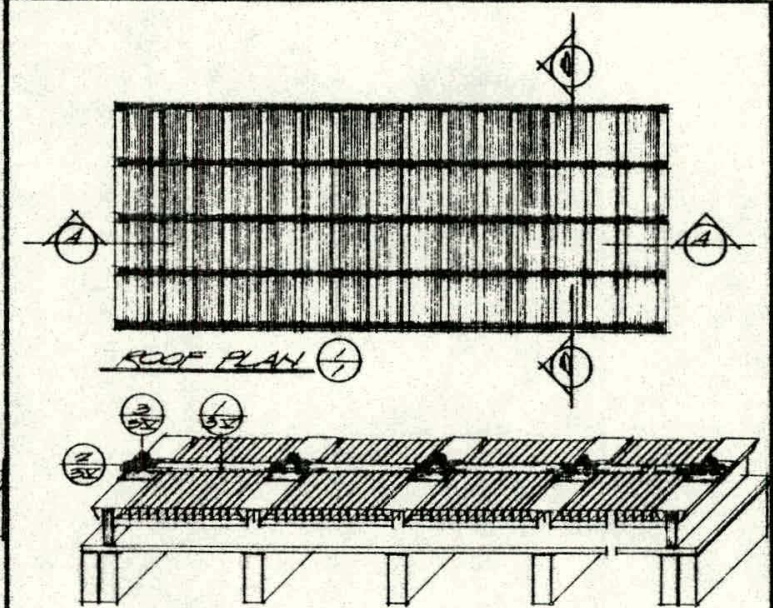

sectroc $4-4$

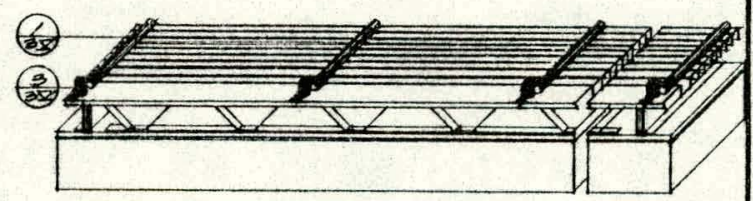

SECTION $2-2$

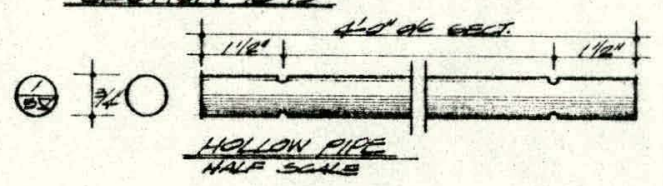

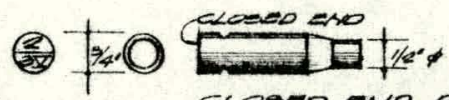

chove ave pipe preas

(32)
VI GLAZING A AASCIAS

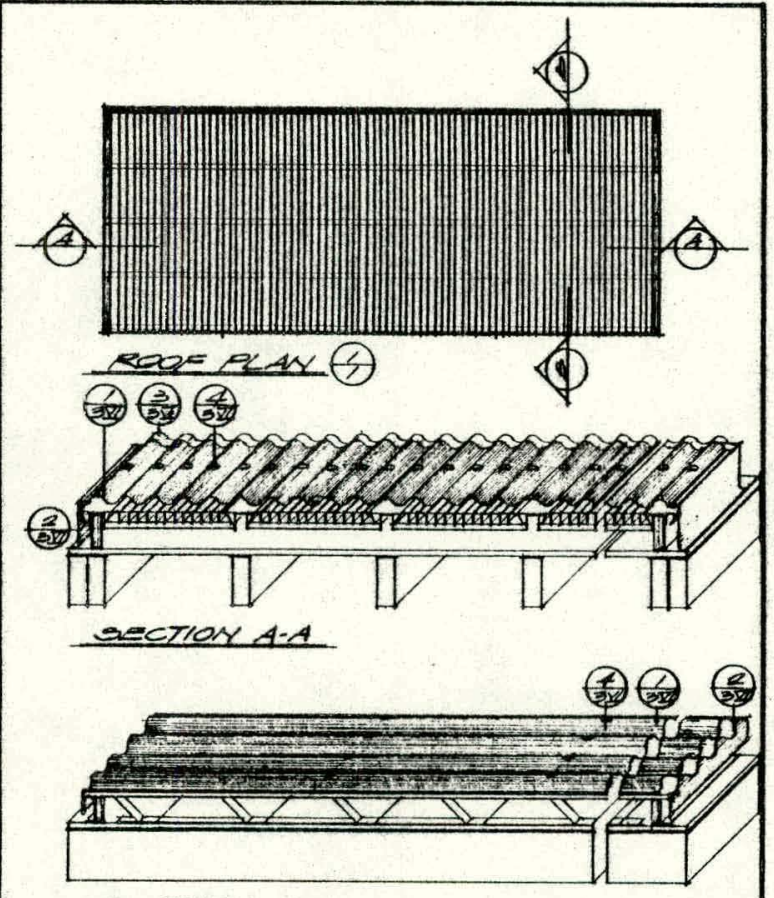

sectrox e-s

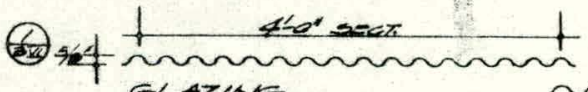
setane

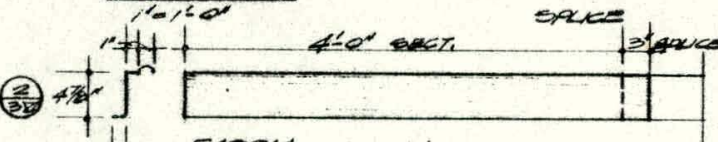

ift eseat

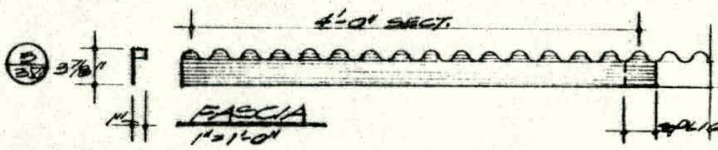

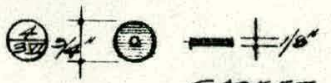

thessy

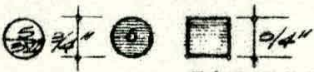
experesece 
THIS PAGE

\section{WAS INTENTIONALLY LEFT BLANK}




\section{DES IGN SCHEME IV}

\section{A. Construction Sequence Description}

The intent behind this design is to use metal rafter construction as an integral part of the solar collector, with the air passage between the rafters. The absorber plate and the glazing are laid out on top of the rafters. Metal rafters are specified because wooden rafters would be expected to fail under the approximately $300 \mathrm{~F}$ temperatures likely to be encountered under stagnation conditions. While this restriction limits the applicability of this design to new construction, we feel that this design has a good chance to be very cost effective, since most of the collector structure is already present as part of the building.

Drawing 1 shows section views of the collector together with certain details. Drawings 2 and 3 show the construction sequence.

We assume in this design that we begin with an unsheathed roof of metal rafters (Drawing 2, Panel I and Detail ). Nailable metal rafters are available with a curved slot at top and bottom into which nails can be inserted. Alternatively, self-tapping sheet-metal screws can be used.

The next step is to apply roof sheathing on the underside of the rafters (Drawing 2, Panel II). This sheathing may be of plywood or sheet metal. The sheathing serves its usual rigidity-providing function, but in addition it seals off from below the space between the rafters. After the sheathing is in place blocks of insulation are inserted between the rafters (Drawing 2, Panel III). This insulation reduces heat loss from the solar collector and also helps to protect the sheathing, if plywood, from the high temperatures 
which occur within the collector under stagnation. Some heat transfer will occur through the rafters themselves, and this may necessitate some form of insulating pads between the rafters and the plywood. Alternatively, insulation may be needed behind the sheathing, particularly if sheet metal is used. The next step is the application of the absorber plate (Drawing 2, Panel IV and Section B-B of Drawing 1). The fabrication details of the absorber plate are discussed in the Parts Glossary. Here it is sufficient to know that each absorber plate section is about 27 in. wide, essentially flat but rising at each edge to form an inverted $U$ which allows the piece to be fitted over two adjacent rafters. The absorber plate has rows of fins extending downward; their purpose is to facilitace hear transfer, g1ving a neeled $3: 1$ taliu of absorber plate area to roof area. Each rafter will then support the inverted-U portions of the absorber-plate pieces to its right and to its left. The absorber-plate pieces are seen as being $8 \mathrm{ft}$ long. They will be installed starting at the bottom of the roof and working up, so that higher sections will overlap those below.

The absorber-plate pieces are fastened to the rafters by crimped plates (Drawing 3, Panel $V$ ). These are placed on the rafters after the absorberplate pieces have been installed, and their edges are bent inward around the flanges of the rafter, anchoring the absorber plate. Each crimped plate has a threaded post extending upward; the purpose of these posts is to provide points of attachment for the glazing.

The crimped platos which are attached to a given rafter are joined by a thin strip of metal. The purpose of this strip is to insure proper spacing of the crimped plates, so that their posts will register with the pre-drilled holes in the glazing. 
The next step is the installation of the glazing (Drawing 3, Panel VI). Glazing material is now sold in rolls up to 50 feet long and 5 feet wide. In this application we want the strips of glazing to be 51 in. wide, to allow for 4 feet of free width and 3 in. of overlap. In this design, the holes in the glazing through which the posts will protrude are pre-drilled. The strip joining the crimp plates insures proper registration of the posts with the holes in the glazing, as long as the first crimp plate on each rafter is properly positioned. This design calls for a single glazing. Multiple glazings, separated by plastic washers placed over each post between glazings, could easily be accomodated with no additional hardware. We see this possibility as an important strength of this design concept.

The glazing is fastened down with closed-end self-gasketed nuts. These provide a first line of defense against rain leakage, but any water which does enter either there or at the glazing overlap lines would be drained off by the absorber plate itself.

The sides and the bottom end of the collector/roof are finished with fascias ( $D$ for side, $D$ for end; see also Drawing 3, Panel VI). The top end, in one type of application, would meet the roof beam, and so no fascia would be needed there. Drawing 1 is simplified to the extent that it does not show the upper end in detail. The upper end could be treated in a number of different ways. The last rafter on each side will be a channel, rather than a nailable I-shaped beam section. In order for the crimp plates to hold firmly to the channel, holes will be needed to be punched in its side (DI

At the lower end, provisions will need to be made to allow water to escape from the absorber plate. One plan is to allow the water to drip down to the 
bottom of the end channel and flow out through small exit holes. In Detail

(D3), the $1 / 4$ in deep space is indicated, and the exit holes would be located below the fascia screw in that detail. The last foot or so of collector would be completely packed with insulation up to the absorber plate. This would provide a pressure seal above the water exit path.

\section{B. Parts Glossary}

The parts are described in the order in which they are applied during construction. Below is an alphabetical parts list, followed by the number of the article describing the part in this glossary. Parts which are integral to the building, such as rafters, sheathing, and insulation, are not described in this section.

\section{PART}

Absorber Plate

Fascia, End

Fascia, Side

Glazing

Plate, Crimperd

ARTICLE NO. IN GLOSSARY

1

4

5

3

2

1. Absorber Plate (Drawing 3, Panel IV; Drawing 1, Section A-A)

Overall dimensions $8 \mathrm{ft} \times 27$ in. Nominal thickness $0.030 \mathrm{in}$, as a sandwich with a top layer of 0.012 in. steel, a bottom layer of 0.012 in.steel, and a nominal bonding agent thickness of 0.006 in.

The top layer, in addition to being shaped into an inverted $U$ on each side so that it can fit over the rafters, has its central flat portion stamped with narrow lateral ridges every 2 in. Their purpose is to provide rigidity to the absorber plate, preventing it from flexing up or down. 
The bottom layer is stamped out, rather like a cheese grater, to provide fin area. In the limit where the interstices between the fins have neglible area, the ratio of heat transfer area to covered roof area would be $3: 1$.

The adhesive joining the two layers could be an epoxy or a silicone rubber adhesive. We think the latter has more potential, since the degree of surface cleanliness required for successful epoxy bonding may drive costs up unduly.

\section{Crimped Plates (Drawing 3, Pane $1 \mathrm{~V}$ )}

Overall dimensions 2 in. $\times 3$ in. Flanges extend downward $11 / 2$ in. Threaded posts extend upward $3 / 4$ in. Nominal thickness 0.120 in. Crimped plates joined by a metal strip 1 in, wide, 0.012 in thick. Separation of plates along strip 24 in. on centers.

3. Glazing (Drawing 3, Panel VI)

The glazing is to be a fiberglass-impregnated plastic such as "Kalwall" or "Filon". It is currently manufactured in $5 \mathrm{ft} \times 50 \mathrm{ft}$ rolls. We will assume a width of 51 in. and a length equal to the horizontal dimension of the collector, which for our design example is $32 \mathrm{ft}$. Glazing thickness is 0.040 in.

4. End Fascia (

Overall dimensions 51 in. $\times 6$ in. Flange extends 2 in. Nominal thickness $0.016 \mathrm{in.}$ This fascia is attached to the channel which forms the lower end of the roof, and to the post of the first crimped plate on each rafter. 5. Side Fascia (

Overall dimensions 51 in. $\times 6$ in. Flange extends 2 in. Nominal thickness $0.016 \mathrm{in}$. This fascia is attached to the channel which forms the side of the roof, and to the posts of the crimped plates on that channel. 


\section{Materials Specifications and Design Options}

The primary fabrication material for this design is steel, since the metal rafters are steel and we do not want different metals to come into contact.

Flat glazing is to be used. No glazing supports are provided between the rafters, and corrugated glazing would accordion downward and rest on the absorber plate.

\section{Acknowledgements}

We thank J. Garry Cottingham for inspiration and for many of the ideas contained in these designs, and Mike Peragine for the drawings and for information concerning accepted architectural practice.

\section{References}

1. Whillier, A., Low Temperature Engineering Applications of Solar Energy;

"Design factors influencing collector performance", ASHRAE, New York, 1967.

2. Solar Assisted Heat Pump Study for Heating and Cooling of Military

Facilities, Phase 1 of 3 Phases, Dubin-Bloome Associates, New York, 1976. 


\section{SC:HEME \&}

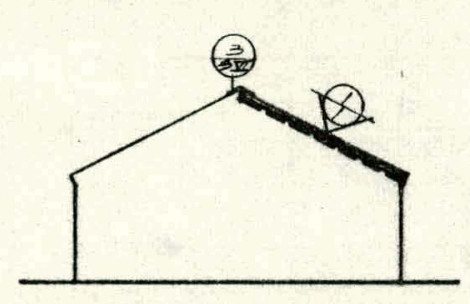

KEY ELEVATION

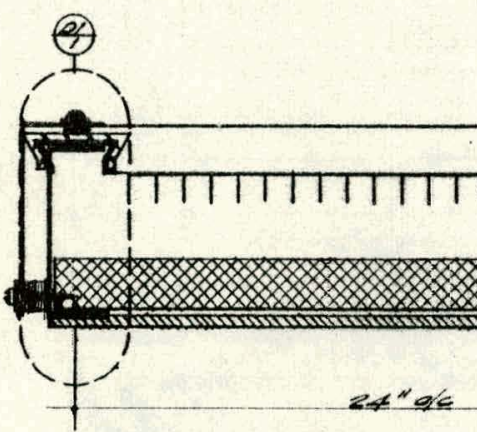

SECTION A-A

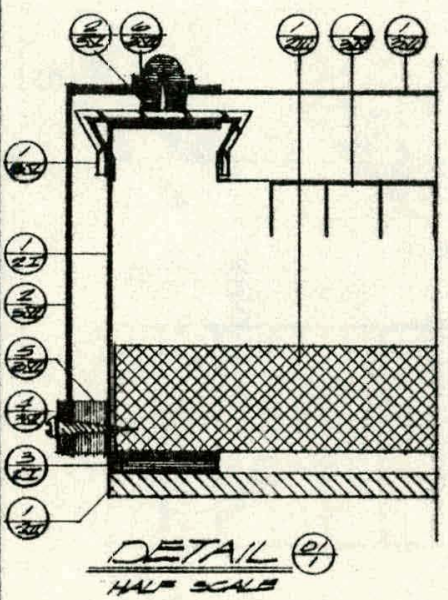

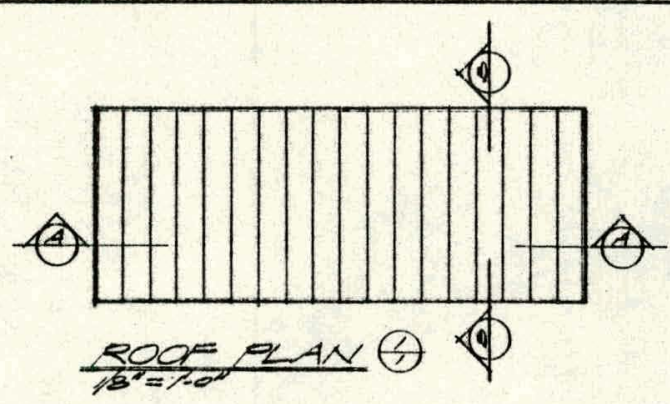

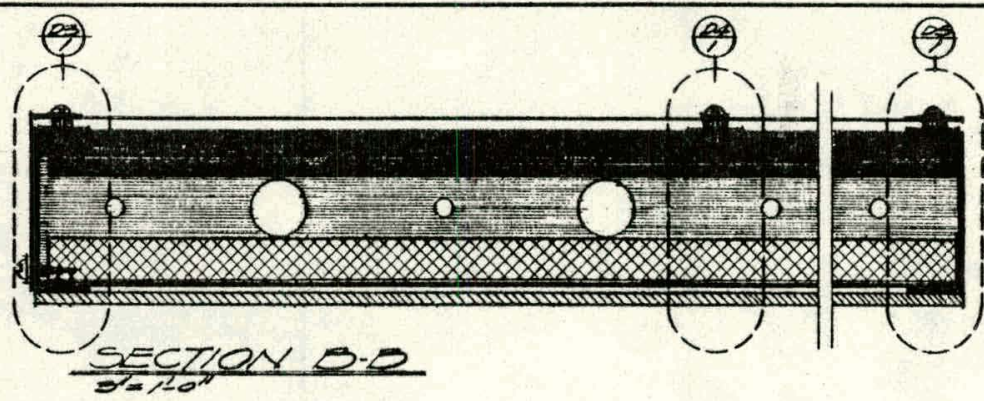
SEcTiON B.D

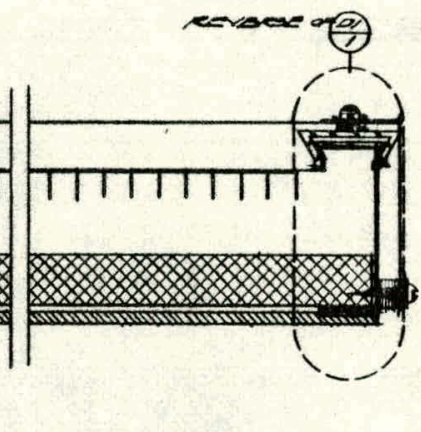

(2)
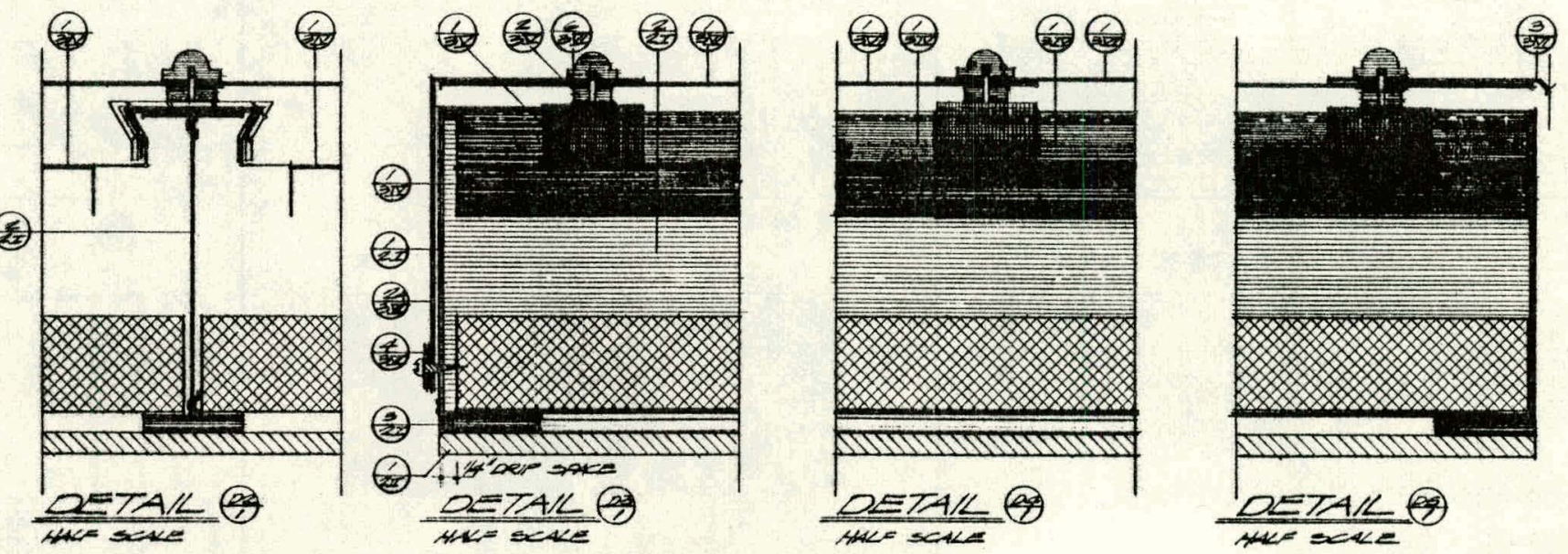


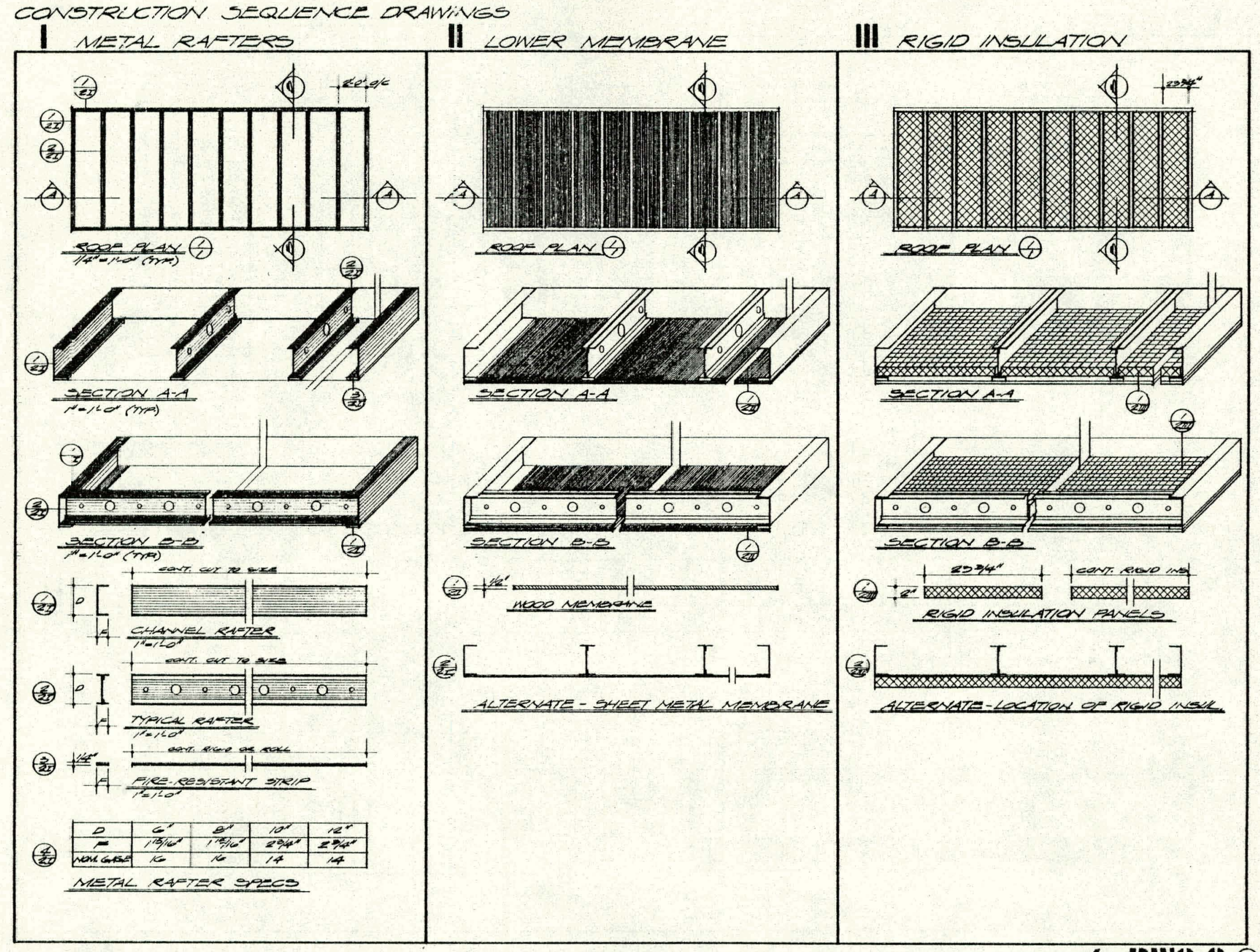




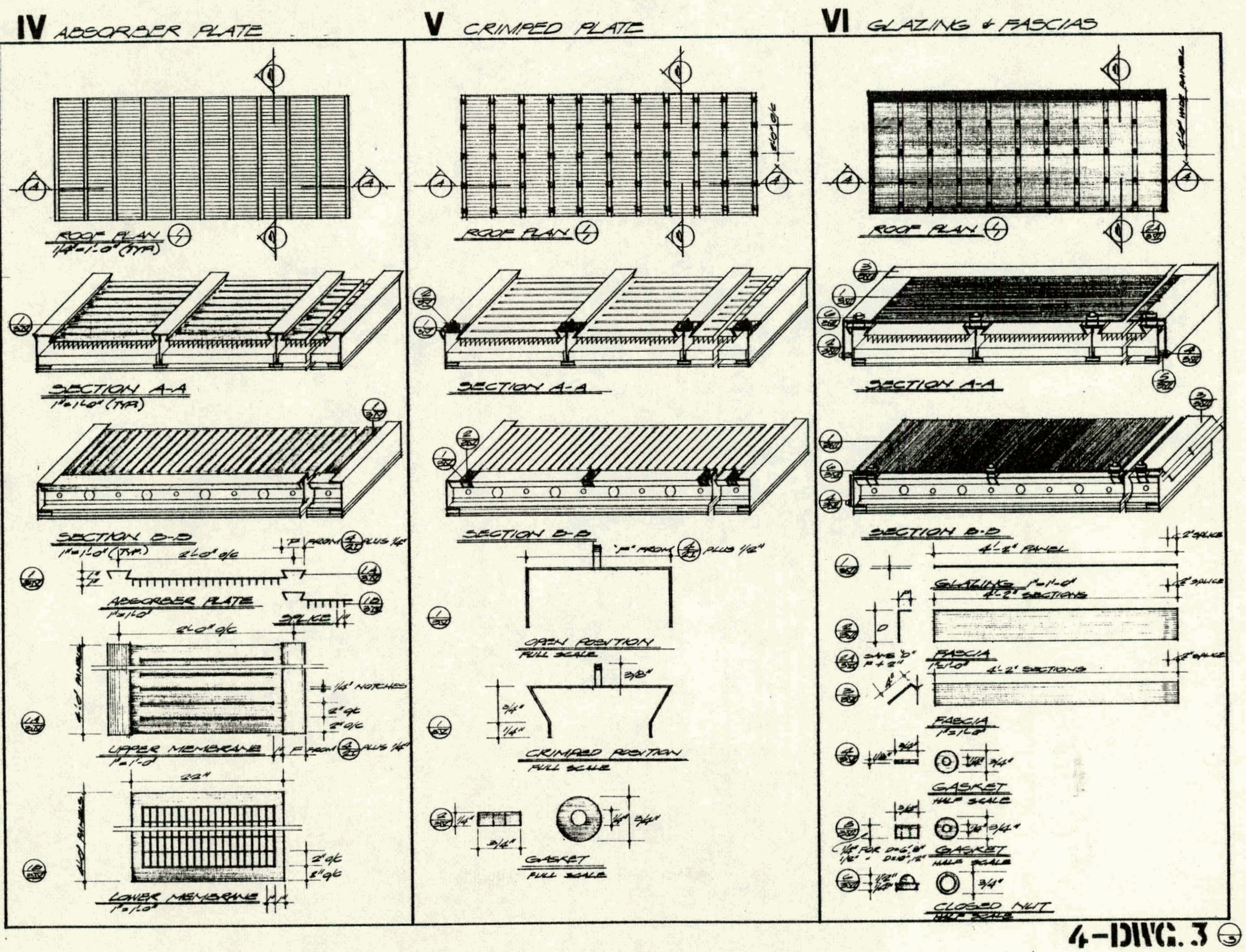

Figure 12. Scheme IV, Drawing 3 Construction Sequence 